\title{
Brics, uma alternativa de poder?
}

\author{
BRICS AN ALTERNATIVE POWER?
}

\author{
Leila Bijos * \\ Erick Pessôa Guilhon **
}

Resumo: Este artigo analisa o crescimento da participação dos BRICS nos processos decisórios mundiais. Analisam-se, igualmente, os índices de crescimento econômico e os fluxos comerciais de Brasil, Rússia, Índia, China e África do Sul (BRICS) e as implicações desses dados para o incremento de poder e de influência desses países no sistema internacional, mormente nas negociações econômico-comerciais em foros e coalizões multilaterais, tais como Organização Mundial do Comércio (OMC), Fundo Monetário Internacional (FMI) e G20 Financeiro. O método utilizado foi uma pesquisa empírica, empregando-se dados qualitativos e quantitativos e raciocínio dedutivo, que provaram que os BRICS estão em fase de consolidação como alternativa de poder às tradicionais potências europeias, aos Estados Unidos e ao Japão. Justifica-se o trabalho pela conveniência de entender a crescente importância de Brasil, Rússia, Índia, China e África do Sul para as decisões econômicas internacionais e para a configuração multipolar do poder econômico e político. Os resultados sintetizam as constatações quantitativas e qualitativas trazidas à discussão, segundo as

* Leila Bijos: professora adjunta do Mestrado em Direito Econômico Internacional da Universidade Católica de Brasília, doutora em Sociologia e mestre em Relações Internacionais pela Universidade de Brasília, Doutoranda em Direito UniCEUB. Autora de diversos estudos e ensaios sobre política internacional, direito da integração, políticas públicas e sociais, direito econômico sustentado, direitos humanos, direito internacional humanitário.leilabijos@gmail.com

** Erick Pessôa Guilhon: Mestrando em Relações Internacionais da Universidade de Brasília (UnB). Bacharel em Relações Internacionais da Associação de Ensino Unificado de Brasília (AEUDF). erickpssoa@gmail.com quais apresentam os BRICS com crescente poder econômico e político, acenando-os como alternativa de poder aos polos da tradicional política internacional.

Palavras-chave: BRICS. Comércio Internacional. FMI. OMC. Relações econômicas internacionais.

Abstract: This article examines the growth of the BRICS' participation in global decision-making processes. Also it analyzes the rates of economic growth and trade flows among Brazil, Russia, India, China and South Africa (BRICS) and the implications of these data for the increment of power and influence of these countries in the international system, particularly in the economic and trade negotiations in multilateral forums and coalitions, such as the World Trade Organization (WTO), International Monetary Fund (IMF) and G20 financial. The method used was an empirical research, using qualitative and quantitative data and deductive reasoning, which proved that the BRICS are in consolidation phase as an alternative to the traditional European powers, United States and Japan. The 
work is justified by the convenience to understand the growing importance of Brazil, Russia, India, China and South Africa to the international economic decisions and for the multipolar setting of economic and political power. The results synthesize quantitative and qualitative findings brought to discussion, which feature the BRICS with growing economic and political power, waving them as an alternative power to the poles of traditional international politics.

Keywords: BRICS. International Trade. IMF. WTO. International economic relations. 


\section{INTRODUÇÃO}

O conceito dos BRICs foi cunhado pelo economista-chefe da Goldman Sachs, Jim O’Neil, em estudo de 2001, intitulado Building Better Global Economic BRICs. De início, no entanto, a África do Sul não compunha este agrupamento, só posteriormente, na III Cúpula que tomou lugar em Sanya, na China, em 2011, esse país africano pôde formalizar sua adesão ao conjunto daqueles emergentes.

As nações do acrônimo alcançaram visibilidade no sistema internacional pelos bons indicadores macroeconômicos, em especial pelo elevado crescimento do Produto Interno Bruto (PIB). Compreende-se, assim, a relevância de analisálas para vislumbrar o quadro econômico e comercial do mundo contemporâneo.

A eventualidade da criação da sigla BRICs pela Goldman Sachs ensejou uma aproximação, não prevista pelos analistas de relações internacionais, de quatro $^{1}$ atores da sociedade internacional bastante diversos em suas histórias, culturas, formações políticas.Há pouco tempo parecia inimaginável a agremiação desses países em uma sigla que foi tão bem acolhida pelos integrantes.Por que, então, poderiam os BRICS unir-se se possuem características muito contrastantes?

A essa pergunta, Karl Deutsch (1982), ao analisar o aspecto de coalizões em sua obra “Análise das Relações Internacionais”, sustenta que “as coalizões são um instrumento essencial para exercer influência e poder tanto em política internacional quanto em política interna” e, dessa maneira, os atores formarão essas coalizões "sempre que, para eles, for mais vantajoso do que permanecer em isolamento”.

Neste século XXI, o surgimento dos chamados “países emergentes”, cada vez mais importantes para a manutenção do crescimento econômico do globo, traz a necessidade de repensar os atuais eixos do poderio internacional e novas maneiras de tratar as relações diplomáticas entre os Estados desenvolvidos e os em desenvolvimento. Ademais, desafia o conjunto dos países a posicionar temas delicados na agenda global com vistas a respostas e soluções imediatas, como é o caso da crise econômica global de 2008.

É exatamente nesse quadro que surgem os BRICS, países emergentes e em consolidação, que, apesar de possuírem características individuais de extrema

\footnotetext{
${ }^{1}$ Como anteriormente assinalado, a África do Sul não fazia parte da criação inicial da sigla BRICs, motivo pelo qual aqui se apontou somente os quatro atores da antiga sigla Brasil, Rússia, Índia e China.
} 
diversificação, enquadram-se na redistribuição de poder de uma nova ordem econômica internacional. A nomenclatura BRICS reúne as iniciais dos países que compõem esse grupo, a saber: Brasil, Rússia, Índia, China e África do Sul (em inglês: South Africa).

De acordo com o Ministério das Relações Exteriores brasileiro, “O acrônimo que designa o agrupamento, originalmente formulado em 2001 pela Goldman Sachs, tem seu foco na esfera econômico-financeira, mas seu escopo de atuação tem abarcado temas comerciais e questões políticas”.

Nesse sentido, o impacto da criação do acrônimo BRICs (atualmente BRICS) consubstanciou a presença desses atores no cenário internacional. Segundo Alexander Zhebit (2010):

A emergência internacional dos BRIC, observada pela Goldman Sachs, mediante a averiguação empírica das taxas aceleradas do crescimento econômico do Brasil, da Rússia, da Índia e da China, vem tornando cada vez mais relativa e difusa a centralidade da liderança econômica das potências ocidentais no sistema internacional, desde os maiores estados-membros da União Europeia até o Japão, evidenciando sinais da redistribuição das capacidades materiais com repercussões nas mudanças estruturais internacionais (ZHEBIT, 2010, p. 8).

As características de institucionalização dos BRICs mudaram desde a criação da sigla. Antes, só havia diálogos em nível ministerial, subsequentemente, esses diálogos, entre os quatro Estados, agora somada a África do Sul, elevaramse ao nível de cúpula, envolvendo presidentes e primeiros-ministros. Isso equivale a um real reconhecimento das afinidades econômicas entre eles e a necessidade de fortalecimento dos laços políticos.

Somadas, realizaram-se até então cinco cúpulas entre os BRICS, são elas:I Cúpula, em Ecaterimburgo, Rússia, 2009;II Cúpula, em Brasília, Brasil, 2010;III Cúpula, em Sanya, China, 2011;IV Cúpula, em Nova Délhi, Índia, 2012; e a V Cúpula, em Durban, África do Sul, em 2013.

Conforme Zhebit (2010), “É evidente que estes quatro países [sic] têm profundas dessemelhanças. Seus regimes políticos, histórias, culturas, religiões e línguas se diferenciam entre si e as distinguem claramente de outras entidades políticas e de outras civilizações durante séculos”. Diante disso, a heterogeneidade na união dos BRICS é, pois, bastante clara em vários pontos.

A vertente econômico-comercial do grupo é expressiva, segundo nota oficial do site da chancelaria brasileira: 
Entre 2003 e 2010, o crescimento dos países do BRICS representou cerca de $40 \%$ da expansão do PIB mundial, e seu PIB, calculado pela paridade de poder de compra, atingiu US\$ 19 trilhões, o que corresponde a 25\% da economia mundial. No período de 2003 a 2010, registrou-se aumento de 575\% na corrente de comércio entre o Brasil e os países do BRICS (as trocas passaram de US\$ 10,71 bilhões em 2003 para US\$ 72,23 bilhões em 2010). Já o comércio total entre os países do BRICS passou de US\$ 38 bilhões em 2003 para US $\$ 143$ bilhões em 2009 e para US\$ 220 bilhões em 2010 (estimativa). ${ }^{2}$

Essa forte expressão do comércio intra e extra-BRICS, para alguns estudiosos, como Alexander Zhebit, intensifica o poderio e a imagem desse conjunto de países no cenário internacional. E evidencia, cada vez mais, o quanto o comércio e a economia internacional precisam da participação dessas nações. Essa perspectiva, no entanto, é contraposta por outros especialistas. De acordo com Paulo Roberto de Almeida (2010), a articulação entre os países do acrônimo ainda é deficitária, o que não fortalece sua representatividade no meio internacional, nesse ínterim:

[...] Não se vislumbra, por sinal, como os países do Bric poderiam propor uma agenda econômico-financeira própria, quando lhes faltam requisitos mínimos para atuar nas principais alavancas - monetárias e financeiras - da economia mundial, bem como autoridade política para expressar valores comuns que sejam compartilhados pelos quatro [...] (ALMEIDA, 2010, p. 138).

À vista do exposto, esta pesquisa torna-se explicativa na medida em que relaciona o surgimento dos BRICS à nova configuração multipolar do poder econômico e à crescente representatividade dessas nações na economia internacional. Buscou-se seguir, por meio do raciocínio dedutivo, um procedimento bibliográfico, com levantamento de dados secundários e de material analítico-descritivo já publicado por pesquisadores dos BRICS.

Nesse sentido, por um lado, as projeções econômicas e os dados sistematizados da economia e do comércio de Brasil, Rússia, Índia, China e África do Sul, colhidos nas análises e nas publicações do banco Goldman Sachs, de organismos internacionais como o FMI e de outras fontes oficiais expressam a vertente quantitativa do trabalho. Por outro lado, a análise do conceito de poder, a qual, de maneira indireta, envolverá a teoria do equilíbrio de poder,

${ }^{2}$ III Cúpula do BRICS - Sanya, 14 de abril de 2011. Disponível em http://www.itamaraty.gov.br/salade-imprensa/notas-a-imprensa/iii-cupula-do-brics-sanya-14-de-abril-de-2011. Acesso em: 3 abr. 2012. 
apresenta uma vertente qualitativa e descritiva da pesquisa, bem como a definição de governança global e suas implicações para o processo de democratização das decisões internacionais.

O período de análise deste trabalho compreende o início da criação da sigla em 2001 até o ano de 2011, abarcando, portanto, uma década de existência do diálogo informal do agrupamento e de sua virtual criação.

Pergunta-se: os BRICS são uma alternativa de poder às potências ocidentais tradicionais? Qual o peso de sua participação nas decisões de questões globais, levando em consideração a relevância política, econômica e comercial desses emergentes?

Entende-se pela conveniência em explicar a crescente importância de Brasil, Rússia, Índia, China e África do Sul para as decisões econômicas internacionais e para a configuração multipolar do poder econômico e político. À vista da modificação da realidade internacional nos últimos anos, aponta-se para um aprofundamento da crise de legitimidade na tomada de decisões internacionais pelas tradicionais potências moldadoras da ordem mundial. O equilíbrio de poder mundial neste século XXI modificou-se e possibilitou a diversidade de atores e polos que estão fora do tradicional círculo de poder ocidental Estados Unidos - União Europeia - Japão, o que expressa uma descentralização de decisões e possibilita o surgimento da multipolaridade. Nesse sentido, é relevante recordar que "as formulações do equilíbrio de poder partem das concepções mais básicas da teoria clássica de que os Estados Nacionais, como entidades soberanas e sem nenhuma autoridade acima da sua, atuam no sistema para preservar sua independência e aumentar seu poder, em um cenário de anarquia” (PECEQUILO, 2008), e que a referida multipolaridade faz parte de um dos muitos possíveis arranjos do poderio no sistema global.

As coalizões são uma possibilidade para os países enfrentar em conjunto as mais diversas problemáticas que se apresentam hodiernamente. Nesse contexto, a hipótese é a de que os BRICS configurar-se-ão em uma associação cujo peso conjunto em dimensões da política, da economia e do comércio internacionais poderá influenciar as decisões globais, de modo a proporcionar um equilíbrio de poder entre nações desenvolvidas e em desenvolvimento.

Por fim, em continuação à convergência dos BRICS para a formação de uma coalizão, cabe salientar que, além de poder servir como plataforma de negociação, o bloco "abre para seus cinco membros espaço para (a) diálogo, identificação de convergências e concertação em relação a diversos temas; e (b) ampliação de contatos e cooperação em setores específicos”. 


\section{O CONCEITO DE “PODER" NAS RELAÇÕES INTERNACIONAIS}

As relações internacionais são permeadas de conceitos e definições clássicos que foram moldados ao longo dos tempos, desde a afirmação de um novo arranjo político - o Estado-nação -, garantido no "Congresso que criou os Tratados de Westfália entre 1644 e 1648 no final da Guerra dos trinta anos” (WIGHT, 2002).

Nesse marco temporal, as identidades das recém-criadas unidades políticas foram construídas e a necessidade de ampliar recursos para a defesa dos territórios em consolidação foi percebida. A posse de um vasto território, de recursos geográficos, de poder militar e de poder econômico, com vistas à manutenção da independência e do nascente conceito de soberania, tornaramse necessidades impostas, as quais criaram constantes guerras, como se vê na obra “Ascensão e Queda das Grandes Potências”(KENNEDY, 1991).

De início, além do conceito de anarquia, é possível vislumbrar outro conceito-chave recorrente no sistema de estados e de fundamental importância para as novas nações, qual seja o conceito do poder.

As definições de poder foram constantemente pensadas e discutidas pela filosofia política (LEBRUN, 1984). Sua aplicação é ampla e aborda os estudos da política interna e da política internacional, e utiliza-se da formulação de termos como poder político, poder militar, poder econômico, entre diversos outros. De acordo com Morgenthau (2003), “A política interna e a política internacional nada mais são do que duas manifestações diferentes do mesmo fenômeno: aluta pelo poder”.

O poder sempre esteve ligado às necessidades circunstanciais das épocas, motivo pelo qual diversas guerras foram promovidas pelas nações com finalidade de alcançar objetivos hegemônicos e, assim, de possuir abundantes recursos de ordem econômico e militar, os quais julgavam ser de seus "interesses vitais”(WIGHT, 2002).

Nessa esteira, segundo Gérard Lebrun (1984), “O nascimento do poder deve-se, aparentemente, às necessidades da guerra”, o que se mostra muito provável, haja vista as lutas que perduraram desde o século $\mathrm{XV}$ ao $\mathrm{XX}$, com pequenas pausas, possibilitando um efetivo equilíbrio de poder mundial.

Em sintonia com esses significados sobre o poder, Mario Stoppino (1997), de modo genérico, em verbete do Dicionário de Política, de Norberto Bobbio, aduz que "a palavra Poder designa a capacidade ou a possibilidade de agir, de 
produzir efeitos”. Essa conceituação parece demasiadamente objetiva, no entanto exemplifica com clareza a concepção da palavra em análise.

Retomando Gérard Lebrun (1984), este autor propõe que:

Em suma, o poder não é um ser, "alguma coisa que se adquire, se toma ou se divide, algo que se deixa escapar”. É o nome atribuído a um conjunto de relações que formigam por toda a parte na espessura do corpo social (poder pedagógico, pátrio poder, poder do policial, poder do contramestre, poder do psicanalista, poder do padre, etc., etc.).(LEBRUN, 1984, pp. 20-21, grifos do autor).

Por seu turno, Keohane \& Nye (2001) pensam o poder”Power can be thought of as the ability of an actor to get others to do something they otherwise would not do (and at an acceptable cost to the actor)". E acrescentam que "Power can be conceived in terms of control over outcomes".

Em face dessas definições, verifica-se que o poder faz parte de uma gama de condições inerentes à realidade dos Estados e que, assim, sua existência pressupõe recursos de uso potencial e pleno. Ademais, é de se observar que, apesar do surgimento de novos atores nas relações internacionais, os "Estadosnações constituem e constituirão os principais centros de poder mundial" (DEUTSCH, 1982).

Robert Keohane \& Joseph Nye (2001), os teóricos da interdependência complexa, criaram as definições de soft e hard power, com clara ligação às de highpolitics e lowpolitics ${ }^{3}$ apresentadas nos debates de relações internacionais dos anos 60. Observe-se que, às vezes, essas conceituações acadêmicas acabam sendo absorvidas pela diplomacia de um ou outro país ${ }^{4}$. De acordo com os autores Keohane e Nye (2001):

\footnotetext{
${ }^{3}$ Segundo Eiiti Sato, "A separação entre high politics e low politics deixou de existir e novos itens passaram a ocupar lugar de destaque: meio ambiente, narcotráfico, as novas bases da competitividade internacional, direitos humanos, conflitos étnico-religiosos, entre outros”. Isso porque, de acordo com este mesmo autor, "'alta política' ou 'grande política' (high politics), que definia o jogo de forças e as grandes estratégias de segurança internacional”, era uma expressão do aspecto militar e político de uma ação, uma vez que, a título de exemplificação, "a corrida armamentista entre a OTAN e o Pacto de Varsóvia ocupava lugar de destaque, ao lado de focos de tensão”. Por outro lado, “As iniciativas e instâncias representadas por instituições como o GATT ou o FMI e as questões sociais eram classificadas como 'baixa política' (low politics) indicando, claramente, que ocupavam posição secundária na agenda internacional” (SATO, 2000, pp.138-139).

${ }^{4}$ Os Estados Unidos é um exemplo de país cuja diplomacia, por vezes, adota terminologias criadas nos meios acadêmicos. As noções de soft and cooptive power e de hard power foram absorvidas pela política externa norte-americana, bem como a criação de um novo termo: o smart power.
} 
Hard power is the ability to get others to do what they otherwise would not do through threat of punishment or promise of reward. [...] Soft power, on the other hand, is the ability to get desired outcomes because others want what you want; is the ability to achieve desired outcomes through attraction rather than coercion (KEOHANE \& NYE, 2001, p. 220).

Nesse contexto, por um lado, o hard power é manifesto no entrelaçamento do poder militar, da coerção, do uso da força, com as decisões tomadas em nível político, e representam o aspecto “duro” da política internacional; por outro, o soft power diz respeito às questões de importância econômica, cultural, propagandísticas, ideológicas, lançadas por uma potência e o quão rápido esses valores são absorvidos por outras nações (KEOHANE \& NYE, 2001).

Nesse sentido, a clássica teoria do equilíbrio de poder, aplicada no que concerne à multiplicidade de atores para manutenção do poder global, e em consonância com o que Deutsch sustenta - seguindo o pensamento do cientista político Morton A. Kaplan - de que é "preciso haver pelo menos cinco grandes potências, ou 'atores essenciais', no mundo” (DEUTSCH, 1982) para a ocorrência desse equilíbrio, assegura a validade do quadro atual das relações internacionais contemporâneas, com o surgimento dos países emergentes do acrônimo BRICS no contexto de equilíbrio de poder mundial.

Na linha do argumento exposto de que algumas nações assimilam conceitos acadêmicos, uma nova terminologia surgiu nos Estados Unidos, qual seja a do smart power [em tradução livre: “poder esperto”]. Segundo a Secretária de Estado Hillary Clinton, em palestra ${ }^{5}$ realizada em 9 de setembro de 2011, na John Jay School of Criminal Justice, em New York, o smart power é “[...] a strategy that integrates all our foreign policy tools - diplomacy and development hand-in-hand with defense - and that advances our values and the rule of law".

Na esteira desse conjunto de definições sobre o abstrato termo 'poder' é possível visualizar certa correlação entre a chegada dos BRICS no palco internacional e o dinamismo no processo corrente da multipolaridade e da governança global.

${ }^{5}$ CLINTON, Hillary. A Smart Power Approach to Counterterrorism. John Jay College of Criminal Justice. 9 set. 2011. Discurso disponível em http://www.state.gov/secretary/rm/2011/09/172034.htm. Acesso em: 10 set. 2012. 
Ante a isso, é válido notar os indiscutíveis dados que legitimam a presença dos BRICS no contexto atual. Segundo a Embaixadora Maria Edileuza Fontenele Reis (2012), "Subsecretária-Geral Política II do Ministério das Relações Exteriores e sherpa ${ }^{6}$ do Brasil nos BRICS e no IBAS”:

Atualmente, os países dos BRICS representam 43,03\% da população mundial, $18 \%$ do Produto Interno Bruto (PIB) nominal mundial (25\% do PIB per capita), 25,91\% da área terrestre do planeta e 46,3\% do crescimento econômico global de 2003 a 2008. Ademais, de acordo com a previsão divulgada pelo FMI em 24 de janeiro de 2012, os países do grupo deverão contribuir com 56\% do crescimento do PIB mundial em 2012. (REIS, 2012, p. 34).

Em relação a essa dimensão dos BRICS, a referida Embaixadora continua:

Sobressaem, ainda, diversas outras características dos membros do agrupamento Brasil, Rússia, Índia e China são os únicos países - além dos EUA - que possuem ao mesmo tempo (a) área territorial acima de dois milhões de quilômetros quadrados, (b) população acima de 100 milhões de pessoas e (c) PIB nominal acima de US\$1 trilhão. (REIS, 2012, pp. 34-35).

Embora os BRICS constituam um mecanismo de diálogo informal, porque o grupo "Não tem um documento constitutivo, não funciona com um secretariado fixo nem tem fundos destinados a financiar qualquer de suas atividades”, características estas que definem a formalização de um efetivo grupo nas relações internacionais, "o que sustenta o mecanismo é a vontade política de seus membros”. Dessa forma, “o BRICS tem um grau deinstitucionalização que se vai definindo, à medida que os cinco países intensificam sua interação”. Entretanto, os componentes não aparentam qualquer desejo de convergência no sentido de solidificar a associação com aqueles mecanismos assinalados.

Com efeito, a aplicabilidade do poder ao agrupamento dos BRICS leva em consideração o peso da coordenação dos recursos de poder de seus integrantes - alguns apresentados acima pela Embaixadora Maria Edileuza -,

\footnotetext{
${ }^{6} \mathrm{O}$ termo sherpa ou xerpa faz referência aos povos originários do Nepal, os quais se encontram na região montanhosa do Himalaia e que são guias ou carregadores que auxiliam alpinistas na escalada da montanha. A palavra vem da etnia desse povo, composta por shyar (leste) e pa (povo), portanto 'povo do leste'. A acepção aqui aplicada é a de que a Embaixadora Maria Edileuza é quem, pela parte brasileira, coordena e orienta o processo de negociação com os demais componentes do BRICS e do IBAS.
} 
fato que os possibilitam equalizar, nos sistemas multilaterais de negociação, por meio da barganha, os ganhos entre países desenvolvidos e em desenvolvimento.

Apesar de diversos analistas como Paulo Roberto de Almeida (2010) asseverar seja antes de tempo concluir a consolidação do grupo como um contrapeso às potências tradicionais, a perspectiva que se delineia nos curtos e médios prazos, segundo a literatura, para a agenda econômica dos BRICS, é positiva e promissora e as decisões aventadas no cerne dos organismos multilaterais apresentam uma necessidade intrínseca, em particular de Rússia e China, de repensar os valores ocidentais.

A alternativa de poder econômico vislumbrada nos BRICS está em consonância com aumento do protagonismo de seus integrantes. Cada integrante possui qualidades e afinidades com vertentes temáticas das relações internacionais, que, de maneira viável, pode explicar o fato da agremiação desses países.

\section{OS BRICS COMO ALTERNATIVA DE PODER NO SISTEMA INTERNACIONAL}

As relações internacionais são expressão dos contatos estabelecidos entre os Estados modernos e implicam uma série de consequências tanto negativas quanto positivas para o cenário mundial, e, por conseguinte, para os agrupamentos políticos contemporâneos, os Estados, e outros atores que delas fazem parte.

Primordialmente, essas interações apresentam-se em um ambiente desordenado, sob relações de poder ${ }^{7}$, ambiente este ao qual Hedley Bull denominou de sociedade anárquica ${ }^{8}$. O palco internacional é o espaço para os confrontos e desafios de, e para, cada Estado moderno dele integrante, no qual se sabe não haver uma força superior dominante e coercitiva que procure proteger os interesses individuais e coletivos das nações (BULL, 2002).

Em face desses aspectos aparentes de desordem e desarranjos, o poder, em sua multifacetada forma, torna-se regente e propõe uma ordem em torno daquele que o detém em grande escala. Assim, potências com altas capacidades políticas, militares e econômicas põem-se como alternativa ao vácuo de poder existente do caos e disputam a hegemonia (KENNEDY, 1991).

\footnotetext{
${ }^{7} \mathrm{O}$ uso da expressão "relações de poder”, cabível para a análise proposta, é empregado por LEBRUN, Gérard. O que é poder?. Tradução Renato Janine Ribeiro, Sílvia Lara Ribeiro. São Paulo: Abril Cultural; Brasiliense, 1984. p. 107.

${ }^{8}$ Definição de Hedley Bull, teórico da Escola Inglesa de Relações Internacionais.
} 
A alternativa de poder aqui proposta é a do poder econômico associado ao poder político. A suposição de que cinco países emergentes - Brasil, Rússia, Índia, China e África do Sul - figurarão no sistema mundial como potências, em poucos anos, pelo crescente poderio econômico, está lastreada nos fatos e acontecimentos observados no atual cenário internacional.

Neste século XXI, mudanças ocorreram na ordem econômica internacional, como o relativo deslocamento para os países em desenvolvimento do eixo econômico-comercial, em especial os do acrônimo BRICS ora analisado. O crescimento dessas nações, ao que parece, no plano econômico, possibilitou uma projeção internacional mais consistente e segura e influenciou as expectativas de decisão do poder político.

Essas potências intermediárias ${ }^{9}$ aumentaram substancialmente seu peso político e econômico no mundo, com maior ênfase a Brasil, Rússia, Índia e China, principalmente no particular aspecto do comércio internacional. E sinalizam, atualmente, a futuros promissores.

Ante o exposto, apresentam-se elementos que definem o poder econômico, e como ele abarca as contínuas mudanças da ordem internacional no contexto da recente multipolaridade, com o consequente reflexo na associação dos BRICS.

\subsection{A configuração multipolar do poder econômico e os BRICS}

A reconfiguração atual do poder econômico e, em parte, da distribuição do poder político nos regimes internacionais deve-se à flagrante visualização do incremento do "peso do poder" ${ }^{10}$ dos países emergentes no cenário internacional.

De acordo com Karl Deutsch (1982) essa influência ou "peso do poder" dos estados em relações internacionais é entendido como a capacidade com que um ator ou um grupo de atores qualquer pode alterar a probabilidade do desfecho de determinado processo decisório. Assim, os esforços concomitantes dos BRICS, por exemplo, nas negociações para a remodelagem dos regimes econômico-financeiros internacionais, poderão alcançar resultados positivos para

\footnotetext{
${ }^{9}$ Segundo PECEQUILO, citando SENNES, "O debate em torno da classificação do status destes países é ainda mais amplo. De acordo com Sennes, 'Uma multiplicidade de conceitos surgiu para designar a categoria de país intermediário. Todos eles percebiam-no como um grupo específico dentro do sistema internacional que, ao se diferenciar das grandes potências mundiais, não se confundia com a massa de países pequenos ou pouco expressivos nesse sistema. As terminologias empregadas para descrevê-lo foram diversas: países de porte médio, grandes potências regionais, países semiperiféricos, recém-industrializados, países intermediários, países em desenvolvimento mais desenvolvidos' (SENNES, 2003:17)” (SENNES, 2003,apud PECEQUILO, 2008, p. 63).

${ }^{10}$ Termo utilizado por Karl Deutsch em “Análise das relações internacionais”, 1982, p. 38.
} 
o pleito desejado do aumento de suas respectivas quotas no FMI, uma vez que a "Political bargaining is usually a means of translating potential into effects[...]"(KEOHANE \& NYE, 2001). Verifica-se, assim, que, conforme a barganha de cada estado-nação na representação de seu interesse individual ou coletivo, levando em conta os pesos político e econômico relativo de cada membro, o incremento de poder despontará como possibilidade.

É corrente a discussão de que a configuração unipolar do poder econômico internacional, detida pelo Ocidente, vem alcançando relativo esgotamento operacional ${ }^{11}$, e que, com a crise financeira deflagrada nos anos de 2008 e 2009 e provocada no âmago dos países desenvolvidos do mundo capitalista, as economias dos principais países em desenvolvimento não foram tão violentamente atingidas. Nessa linha, de acordo com o diplomata brasileiro Affonso Celso de Ouro-Preto (2011), “A distribuição global de poder econômico parece transitar para uma confirmação multipolar, mas as mudanças não estariam induzindo as transformações correspondentes no plano político”.

Em consonância com esses fatos, Paul Kennedy (1991) já asseverava, quanto à multipolaridade do poder econômico mundial, que, "Deixando de lado todas as nações menores, portanto, é evidente que já existe um mundo multipolar, mais uma vez, se medirmos apenas os índices econômicos” (grifo do autor).

Ainda em continuidade a essa visão, Gilberto Dupas (2009) vaticina que "Estruturas e equilíbrios de poder irão se alterar tanto na política como na economia, e muito exigirão de seus atores principais”. Com isso, para os BRICS, participar de uma configuração multipolar do poder econômico requererá um esforço contínuo na coordenação de políticas macroeconômicas que se sustentem no longo prazo.

Aparentemente, ser uma alternativa de poder às consagradas potências do mundo ocidental demandará um esforço muito maior do que esses emergentes podem estar dispostos a ceder. A busca de uma forte sinergia para reestruturar as dimensões financeira, econômica e política das instituições internacionais modernas, em especial a Organização das Nações Unidas (ONU), o Fundo Monetário Internacional (FMI) e o Banco Mundial, constitui-se, sem dúvida, um passo significativo na conformação de um mundo mais representativo e legítimo.

Desta feita, ao contexto de reestruturação dos principais regimes internacionais, Rússia e China, no entanto, permanecem no imobilismo de reforma da ONU, obstaculizando quaisquer pretensões de redimensionamento do

${ }^{11} \mathrm{O}$ The Economist afirmou que The era of free-market triumphalism has come to a juddering halt, and the crisis that destroyed Lehman Brothers in 2008 is now engulfing much of the rich world. Disponível em http://www.economist.com/node/21542931?fb ref=activity. Acesso em: 30 set. 2012 
Conselho de Segurança ${ }^{12}$. Essa conflitante oposição, está refletida nas declarações de Cúpula dos BRICS, as quais afirmam, em linguagem pouco enérgica, que "China e Rússia reiteram a importância que atribuem a Brasil, Índia e África do Sul nos assuntos internacionais e apoiam sua aspiração de desempenhar papel mais protagônico nas Nações Unidas"13.

Para o subsequente aprofundamento de tais discussões, há que se estabelecer uma diferença terminológica fundamental entre os termos multipolaridade e multilateralismo. Segundo publicação ${ }^{14}$ do BRICS PolicyCenter, intitulada “As Mudanças na Política Externa do Governo Dilma e a 'Multipolaridade Benigna'” (2011), entende-se que:

A multipolaridade não deve ser confundida com o multilateralismo. A primeira se trata de uma estrutura de poder oposta, por definição, à unipolaridade que é a hegemonia de um pólo de poder sobre o sistema internacional, e à bipolaridade - competição entre dois pólos de poder hegemônicos no sistema internacional. Esta estrutura de poder compreende diversos (três ou mais) pólos no sistema internacional e pode ser de caráter competitivo ou cooperativo, como busca caracterizar o novo paradigma de política externa brasileira. A China, por exemplo, pode ser considerado um pólo de poder, assim como a União Europeia e os Estados Unidos. O multilateralismo, por sua vez, refere-se à forma de atuação dos países dentro de uma estrutura de poder no sistema internacional, seja ela unipolar, bipolar ou multipolar. O conceito caracteriza a atuação conjunta dos países no sistema internacional, em oposição ao unilateralismo, que seria a atuação isolada e arbitrária de um determinado país. As organizações internacionais, como a OMS (Organização Mundial da Saúde), a OMC (Organização Mundial do Comércio) e a ONU (Organização das Nações Unidas) são exemplos de fóruns multilaterais, dado que neles os países atuam e tomam decisões em conjunto. Do ponto de vista da política externa de um país, o multilateralismo diz respeito à decisão de atuar no sistema internacional por meio destes fóruns, em vez de atuar isoladamente.

Esclarecidas essas importantes questões conceituais, passa-se a analisar os dados de economia e de comércio que embasam a configuração multipolar do poder econômico com a inclusão dos BRICS.

\footnotetext{
${ }^{12}$ For Group of 5 Nations, Acronym Is Easy, but Common Ground Is Hard. Disponível em http:// www.nytimes.com/2012/03/29/world/asia/plan-of-action-proves-elusive-for-emerging-economies-inbrics.html?pagewanted=1. Acesso em: 30 set. 2012.

${ }^{13}$ Declaração de Nova Délhi, IV Reunião de Cúpula dos BRICS, 29 de março de 2012. Disponível em http://www.itamaraty.gov.br/sala-de-imprensa/notas-a-imprensa/quarta-cupula-dos-brics-nova-delhi29-de-marco-de-2012-parceria-dos-brics-para-a-estabilidade-seguranca-e-prosperidade-declaracao-denova-delhi. Acesso em: 30 set. 2012.

${ }^{14}$ Disponível em http://bricspolicycenter.org/homolog/uploads/trabalhos/132/doc/556584881.pdf. Acesso em: 30 set. 2012.
} 


\section{OS BRICS NA ECONOMIA E NO COMÉRCIO INTERNACIONAL}

Brasil, Rússia, Índia, China e África do Sul (BRICS) figuram, nos últimos dez anos, no sistema internacional, como economias dinâmicas e com potencial de desenvolvimento. A visualização das taxas de crescimento do PIB dessas nações estimulou organismos internacionais a aprofundarem o conhecimento sobre esses estados emergentes.

Nesse sentido, a tabela abaixo apresenta as taxas de crescimento do PIB dos BRICS no período de dez anos:

TABELA 1 - PIB (EM \%) DOS BRICS, DE 2001 A 2011

\begin{tabular}{|c|c|c|c|c|c|}
\hline Anos & Brasil & Rússia & Índia & China & $\begin{array}{c}\text { África } \\
\text { do Sul }\end{array}$ \\
\hline 2001 & $1,30 \%$ & $5,10 \%$ & $3.9 \%$ & $8.3 \%$ & $2.7 \%$ \\
\hline 2002 & $2,70 \%$ & $4,70 \%$ & $4.6 \%$ & $9.1 \%$ & $3.7 \%$ \\
\hline 2003 & $1,10 \%$ & $7,30 \%$ & $6.9 \%$ & $10.1 \%$ & $2.9 \%$ \\
\hline 2004 & $5.7 \%$ & $7.2 \%$ & $7.6 \%$ & $10.1 \%$ & $4.6 \%$ \\
\hline 2005 & $3.2 \%$ & $6.4 \%$ & $9.0 \%$ & $11.3 \%$ & $5.3 \%$ \\
\hline 2006 & $4.0 \%$ & $8.2 \%$ & $9.5 \%$ & $12.7 \%$ & $5.6 \%$ \\
\hline 2007 & $6.1 \%$ & $8.5 \%$ & $10.0 \%$ & $14.2 \%$ & $5.5 \%$ \\
\hline 2008 & $5.2 \%$ & $5.2 \%$ & $6.9 \%$ & $9.6 \%$ & $3.6 \%$ \\
\hline 2009 & $-0.3 \%$ & $-7.8 \%$ & $5.9 \%$ & $9.2 \%$ & $-1.5 \%$ \\
\hline 2010 & $7.5 \%$ & $4.3 \%$ & $10.1 \%$ & $10.4 \%$ & $2.9 \%$ \\
\hline 2011 & $2.7 \%$ & $4.3 \%$ & $6.8 \%$ & $9.2 \%$ & $3.1 \%$ \\
\hline
\end{tabular}

Fontes: Elaboração própria com base nos dados do Fundo Monetário Internacional (FMI); World Economic Outlook (October, 2009): Sustaining the Recovery; World Economic Outlook (October, 2010): Recovery, Risk, and Rebalancing; e World Economic Outlook (October, 2012): Coping with High Debt and Sluggish Growth. Também disponível em http:// data.worldbank.org/indicator/NY.GDP.MKTP.KD.ZG. Acesso em: 30 set. 2012. 
A escolha do PIB como elemento de análise dessas economias emergentes é pertinente não só porque, conforme Mankiw (2001), “Ao julgar o sucesso da economia, é natural observar a renda total gerada na economia”, incumbência esta detida pelo produto interno bruto (PIB), mas também porque, consoante Krugman e Obstfeld (2010), "Há muito tempo, a maioria dos países tem usado o produto interno bruto (PIB) [...] como principal medida da atividade econômica nacional”.

O PIB é definido como "o valor de mercado de todos os bens e serviços finais produzidos em um país em dado período” e as funcionalidades básicas de análise são que "O PIB mede duas coisas simultaneamente: a renda total gerada na economia e a despesa total com os bens e serviços produzidos na economia" (MANKIW, 2001).

A Tabela 1 acima apresentada desatende a quaisquer outros valores das estimativas econômicas e foca sua exposição tão somente no crescimento percentual do PIB de cada BRICS. Portanto, apresenta a consolidação do crescimento, no período de 2001 - data da criação do acrônimo BRIC - a 2011, segundo informações das publicações do Fundo Monetário Internacional (FMI).

Adicionalmente a isso, em termos de PIB em dólares, para se registrar a dimensão econômica dos BRICS e comparar o crescimento de cada componente, no período de uma década (2001-2011), apresentam-se, a seguir, esses valores, de acordo com o World Development Indicators (WDI), do Banco Mundial:

A Tabela 2 acima mostra o extraordinário crescimento do PIB de cada país e, em particular, do salto da China, que teve aumento de US\$1,32 trilhões, em 2001, para US\$7,32 trilhões, em 2011, um crescimento de 452\% (ou US\$ 5,99 trilhões). Parte dessa variação do PIB pode ser explicada pela inflação em dólares e em razão de alterações cambiais.

Os dados da Tabela 2 mostram, ademais, que o PIB da África do Sul é bem inferior ao dos demais países. Em 2011 era de US\$ 408 bilhões. Comparando-se aos outros BRICS encontra-se, aproximadamente, quatro vezes aquém do de Rússia e Índia, seis vezes do PIB do Brasil e dezessete vezes do da China, o que suscitou desconhecimento pelo criador da sigla quanto à inclusão da África do Sul no rol desses grandes emergentes ${ }^{15}$.

\footnotetext{
${ }^{15}$ Jim O’Neill, durante o seminário "Mercados de Crescimento Elevado", promovido pela revista The Economist em Londres, afirmou que "A África do Sul não tem a mesma magnitude econômica dos outros países BRIC" e que "Eu não reconheço o 'S' do BRICS”. Disponível em http:// economia.estadao.com.br/noticias/economia,criador-do-termo-bric-nao-considera-africa-do-sul-partedo-grupo,86339,0.htm. Acesso em: 26 out. 2012.
} 
TABELA 2 - PIB EM BILHÕES DE DÓLARES, DE 2001 A 2011, DOS BRICS ${ }^{16}$.

\begin{tabular}{|r|r|r|r|r|r|}
\hline \multicolumn{1}{c|}{ Anos } & \multicolumn{1}{c|}{ Brasil } & \multicolumn{1}{c|}{ Rússia } & \multicolumn{1}{c|}{ Índia } & \multicolumn{1}{c|}{ China } & \multicolumn{1}{c|}{$\begin{array}{c}\text { África do } \\
\text { Sul }\end{array}$} \\
\hline $2.001,00$ & 553,58 & 306,60 & 492,38 & $1,324,81$ & 118,48 \\
\hline $2.002,00$ & 504,22 & 345,11 & 522,80 & $1,453,83$ & 111,10 \\
\hline $2.003,00$ & 552,47 & 430,35 & 617,57 & $1,640,96$ & 168,22 \\
\hline $2.004,00$ & 663,76 & 591,02 & 721,59 & $1,931,64$ & 219,10 \\
\hline $2.005,00$ & 882,10 & 764,00 & 834,22 & $2,256,90$ & 247,06 \\
\hline $2.006,00$ & $1,088,9$ & 989,93 & 949,11 & $2,712,95$ & 261,00 \\
\hline $2.007,00$ & $1,365,9$ & $1,299,7$ & $1,238,70$ & $3,494,05$ & 286,17 \\
\hline $2.008,00$ & $1,652,8$ & $1,660,8$ & $1,224,09$ & $4,521,82$ & 273,87 \\
\hline $2.009,00$ & $1,621,6$ & $1,222,6$ & $1,361,05$ & $4,991,25$ & 283,01 \\
\hline $2.010,00$ & $2,143,0$ & $1,487,5$ & $1,684,32$ & $5,930,52$ & 363,52 \\
\hline $2.011,00$ & $2,476,6$ & $1,857,7$ & $1,847,98$ & $7,318,49$ & 408,23 \\
\hline
\end{tabular}

Fonte: Elaboração própria com base nos dados do World Development Indicators (World Bank, 2012).

Como anteriormente assinalado, os BRICS possuem um inegável peso econômico internacional, em especial a China, somam juntos cerca de $18 \%$ do Produto Interno Bruto (PIB) nominal mundial e detêm uma posição ascendente nesse quadro.

Diante disso, o FMI estima que as economias emergentes continuarão a participar com expressivo peso no crescimento do PIB mundial, com níveis superiores a média global, nos anos de 2012 e 2013, em que pese à recessão econômica internacional.

\footnotetext{
${ }^{15}$ Disponível em http://data.worldbank.org/indicator/NY.GDP.MKTP.CD/countries/1W-BR-CN-INRU-ZA?page=1\&order=wbapi_data_value_2011\%20wbapi_data_value $\% 20$ wbapi_data_valuelast\&sort=asc\&display=default. Acesso em: 26 out. 2012. Observe-se que, segundo este site do Banco Mundial, "Data are in current U.S. dollars. Dollar figures for GDP are converted from domestic currencies using single year official exchange rates. For a few countries where the official exchange rate does not reflect the rate effectively applied to actual foreign exchange transactions, an alternative conversion factor is used".
} 
Finalmente apresentados esses dados macroeconômicos dos BRICS, passa-se a análise da participação dessas nações no processo decisório de algumas organizações econômicas multilaterais internacionais, a saber, FMI, G20 Financeiro e OMC e um pouco da história desses regimes.

\subsection{Os BRICS e as Organizações econômicas multilaterais (FMI, G20 Financeiro e OMC).}

As organizações econômicas multilaterais internacionais como o FMI, o G20 Financeiro e a OMC são importantes pilares para a operacionalização das finanças e do comércio internacionais. O primeiro e o último órgão são fruto do sistema histórico de Bretton Woods, criado com vistas à manutenção da ordem econômica internacional.

Essas organizações proporcionam espaço para a discussão de temáticas que afetam diretamente todos os países do sistema estatal. Adicionalmente, fazem parte do sistema de governança global que será discutido mais adiante.

Abaixo, de maneira sucinta, apresentam-se linhas gerais da participação dos BRICS nesses foros de articulação econômica, em suas dimensões financeira (FMI), comercial (OMC) e nas deliberações econômicas do G20 Financeiro, além de um pouco da história de formação dessas organizações internacionais.

\subsubsection{Fundo Monetário Internacional (FMI)}

A Grande Depressão de 1929 configurou-se, entre outras, uma das razões para a instabilidade que ocasionou a Segunda Guerra Mundial no século XX. Isso porque uma série de medidas protecionistas tomadas pelos países, para evitar a derrocada econômica, gerou um verdadeiro quadro de empobrecimento internacional.

Diante disso, o Fundo Monetário Internacional - FMI - (em inglês International Monetary Fund - IMF) nasceu como "uma experiência inédita” ${ }^{17}$, um mecanismo para articular soluções à combalida economia internacional, após a Segunda Guerra Mundial.

${ }^{17}$ CARVAlHO, Fernando J. Cardim de. A Crise Econômico-Financeira de 2007/2008, o G20 e as Opções para o Brasil. Brasília: FUNAG, 2010. pp. 69-82. 
Resultante, em julho de 1944, das reuniões de Bretton Woods, foi um organismo acordado por 45 países em intensas negociações ${ }^{18}$. Notadamente, "Os Artigos do Acordo do FMI tentaram evitar a repetição da turbulenta experiência no período entre guerras mediante uma mistura de disciplina e flexibilidade” (KRUGMAN \& OBSTFELD, 2010).

A organização em formação refletiu o poder econômico norte-americano, cuja moeda, o dólar, passou a reger as taxas de câmbio fixas. Segundo Krugman \& Obstfeld (2010), “O sistema elaborado pelo acordo de Bretton Woods exigia taxas fixas de câmbio em relação ao dólar norte-americano e um preço do ouro em dólar invariável - \$ 35 por onça”.

Embasado em um processo decisório que favorecia basicamente as nações do Ocidente, segundo o aporte financeiro de cada uma, a tessitura da ordem econômico-financeira não contemplava um processo amplamente democrático e representativo.

Nessa linha, “[...] os países mais avançados sempre detiveram o maior número de quotas no capital votante do FMI, cabendo aos Estados Unidos, em particular, um número suficiente de quotas para permitir ao país bloquear qualquer decisão estratégica que possa não ser de seu interesse” (CARVALHO, 2010).

Observa-se, ademais, que “As fórmulas de cálculo das quotas de cada país membro foram-se alterando com o passar dos anos em função seja da adesão de novos membros, seja de mudanças na geografia econômica internacional, mas a preeminência dos que financiam nunca foi posta em dúvida” (CARVALHO, 2010).

Dentro dessa perspectiva, Brasil, Rússia, Índia, China e África do Sul barganham maior representatividade no FMI, com consequente aumento de suas quotas e do aporte financeiro dado por esses países ao Fundo, de modo a garantir maior influência nas decisões do organismo.

Nas quatro reuniões de Cúpulas dos BRICS, anteriormente mencionadas, as declarações delas resultantes afirmavam nos seguintes teores o desejo desses emergentes de participarem com maior força no âmbito do FMI.

Na primeira Reunião de Cúpula realizada em Ecaterimburgo, Rússia, em 16 de junho de 2009, os BRICS, em declaração emitida, afirmaram, no terceiro ponto, que:

${ }^{18} \mathrm{O}$ site do Fundo Monetário Internacional, em inglês International Monetary Fund, traz breves históricos de sua formação. Disponível em http://www.i.f.org/external/about/histcoop.htm. Acesso em: 20 out. 2012. 
[...] 3. Estamos comprometidos com a promoção da reforma das instituições financeiras internacionais, de modo a que reflitam as mudanças ocorridas na economia mundial. As economias emergentes e em desenvolvimento devem ter voz mais ativa e maior representatividade em instituições financeiras internacionais, e seus diretores e lideranças sênior deveriam ser designados por meio de um processo de seleção aberto, transparente e baseado no mérito. Também acreditamos que há forte necessidade de que seja criado um sistema monetário internacional estável, previsível e mais diversificado.

Nas Cúpulas seguintes as declarações assumiram retóricas mais enérgicas, uma vez que a crise econômica começava a impactar em todo o globo. Com isso, a segunda Reunião de Cúpula realizada em Brasília, Brasil, em 15 de abril de 2010, registrou que:

[...] 11. Nós nos esforçaremos para alcançar uma conclusão ambiciosa para as reformas em curso, e há muito esperadas, das instituições de Bretton Woods. O FMI e o Banco Mundial precisam urgentemente resolver seus déficits de legitimidade. Reformar as estruturas de governança dessas instituições requer, em primeiro lugar, uma mudança substancial no poder de voto, em favor das economias emergentes de mercado e dos países em desenvolvimento, de modo a adequar sua participação nos processos decisórios ao seu peso relativo na economia mundial.

A terceira Cúpula foi mais incisiva, sustentando que:

[...] 16. Ao reconhecer que a crise financeira internacional evidenciou as inadequações e deficiências do sistema monetário e financeiro internacional existente, apoiamos a reforma e aperfeiçoamento do sistema monetário internacional, por meio de um sistema de reservas internacionais abrangente e capaz de proporcionar estabilidade e segurança.

Por fim, a quarta Cúpula deu prosseguimento ao desejo de alavancar a representação dessas nações na arquitetura financeira internacional, redundando no teor da declaração da primeira Cúpula:

[...] 8. Reconhecemos a importância da arquitetura financeira global para a manutenção da estabilidade e da integridade do sistema monetário e financeiro internacional. Em consequência, demandamos uma arquitetura financeira mais representativa, com a ampliação da voz e da representação de países em 
desenvolvimento e o estabelecimento de um sistema monetário internacional justo e aprimorado, que possa atender o interesse de todos os países e apoiar o desenvolvimento de economias emergentes e em desenvolvimento. Essas economias têm apresentado um expressivo crescimento, contribuindo de forma significativa para a recuperação da economia global.

Essa reivindicação do aumento de participação nas decisões do FMI, como antes aduzido, está diretamente relacionada à ampliação do número de quotas e ao consequente aumento do subsídio financeiro dado por cada BRICS àquela organização. Isso implicará a revisão da fórmula de cálculo das quotas e posterior "transferência do poder de voto em favor das economias dinâmicas sub-representadas” (BALDUINO, 2010).

Individualmente, a porcentagem de participação de cada BRICS nas quotas do FMI são de: 1.79\% “ Brasil; 2.50\% - Rússia; 2.44\% - Índia; 4.0\% China; e $0.78 \%$ - África do Sul ${ }^{19}$. Em detrimento a 17.69\% dos Estados Unidos; 6.56\% do Japão; 6.12\% da Alemanha; 4.51\% da França; e 4.51\% do Reino Unido, é perceptível que os países emergentes da sigla estão representados abaixo de seu real poder econômico ${ }^{20}$.

Segundo Balduino (2010), essa estrutura está em curso de se modificar, porquanto "O FMI havia aprovado uma transferência de quotas em abril de 2008 e nova revisão estava prevista para 2013”.

Diante desse quadro, é visível que, historicamente, “A superrepresentação de países mais avançados no órgão tornou sempre muito difícil a separação, se é que ela existe, entre a busca de interesses cooperativos de toda a comunidade de países membros e a persecução de objetivos nacionais de países dominantes” (CARVALHO, 2010), motivo pelo qual os BRICS buscam remodelar a estrutura econômica internacional vigente, deslocando a geografia econômica mundial em favor das economias emergentes mais participativas neste cenário.

\subsubsection{Grupo dos Vinte (G20 Financeiro)}

A crise asiática de 1997/8 proporcionou a formação do Grupo dos Vinte ou G20 para agregar "advanced and emerging countries of systemic importance".

${ }^{19}$ Dados disponíveis em http://www.imf.org/external/np/sec/memdir/members.aspx\#1. Acesso em: 28 out. 2012.

${ }^{20}$ Idem. 
De acordo com Carvalho (2010), “O G20 nasceu em uma conjuntura muito particular. O grupo foi formado em 1999, na sequência da crise asiática de 1997/8 e suas sequelas, a crise russa de 1998 e a crise cambial brasileira de 1998/9".

Contudo, esse grupo não possuía voz ativa nas decisões econômicas internacionais, restando somente acatar as deliberações discutidas no cerne do G7/8, este composto por Alemanha, Canadá, Estados Unidos, Itália, Japão, Reino Unido, União Europeia, com posterior convite à Rússia para integrá-lo, no entanto esta sem poder de decisão.

O grupo é definido como "the premier forum for international cooperation on the most important aspects of the international economic and financial agenda"21. Sua atuação, pois, não está limitada ao campo financeiro e abrange ampla gama de assuntos econômicos, perpassando também o comércio internacional.

Os países que compõem o G20 Financeiro são África do Sul, Alemanha, Arábia Saudita, Argentina, Austrália, Brasil, Canadá, China, Coreia do Sul, Estados Unidos, França, Índia, Indonésia, Itália, Japão, México, Reino Unido, Rússia, Turquia e União Europeia. Essa dimensão é mais representativa que o G7/8, uma vez que agrega as maiores e mais dinâmicas economias emergentes dos cinco continentes.

No entanto, este agrupamento não foi sempre relevante. Como afirma Baumann (2012), “O G20 foi formado em plena situação de crise internacional. Sua elevação de status, como foro de discussão, esteve desde o início relacionada com a percepção de que os debates apenas no âmbito do G8 deixavam de fora atores de importância econômica crescente”.

Com efeito, é de se vislumbrar, nessa perspectiva de Baumann (2012), que o crescimento econômico irrompido nas potências intermediárias foi o fato que as alçou ao patamar de relevância política em que hoje se encontram. Dessa forma, Brasil, Rússia, Índia, China e, menor grau, África do Sul puderam, efetivamente, entrar no círculo das grandes potências.

Ainda no que concerne ao G20 financeiro, segundo o site oficial do agrupamento, seus objetivos são “1. Policy coordination between its members in order to achieve global economic stability, sustainable growth; 2. To promote financial regulations that reduce risks and prevent

${ }^{21}$ Disponível em http://www.g20.org/docs/about/about G20.html. Acesso em: 28 out. 2012. 
future financial crises; and 3. To create a new international financial architecture" 22 .

O terceiro objetivo, acredita-se, é o de maior atenção para os BRICS. Haja vista que a demanda feita por esses países é no sentido da reforma dos regimes internacionais, principalmente os de cunho econômico, de modo que absorvam as nações em desenvolvimento mais representativas e, conseguintemente, ampliem os escopos de existência dessas instituições.

Em geral, atualmente, analistas das relações internacionais acreditam que, com a ascensão econômica dos BRICS e de outros países emergentes no cenário internacional, necessariamente, a influência política será aumentada e a reconfiguração das cúpulas decisórias mundiais terá de ocorrer para acomodálos, sob pena das principais organizações internacionais perderem legitimidade.

Logo, segundo Baumann (2012), "Um fórum que é candidato natural para os BRICS concentrarem sua pressão é o chamado G20 financeiro" porquanto "Aí estão representados os países que em conjunto detêm a maior parte dos votos nos principais organismos multilaterais e correspondem a $85 \%$ do PIB mundial”. O G20 Financeiro configura-se, assim, um espaço de alta relevância para atuação dos BRICS na finalidade exposta.

\subsubsection{Organização Mundial do Comércio (OMC)}

A Organização Mundial do Comércio (OMC) é o órgão de instrumentalização das negociações comerciais internacionais. Ela é "the only global international organization dealing with the rules of trade between nations. At its heart are the WTO agreements, negotiated and signed by the bulk of the world's trading nations and ratified in their parliaments"23.

Segundo Vera Thorstensen (1998):

Dentro do contexto internacional, a OMC, criada em janeiro de 1995, é a coluna mestra do novo sistema internacional do comércio. A OMC engloba o GATT, o Acordo Geral de Tarifas e de Comércio, concluído em 1947, os resultados das sete negociações multilaterais de liberalização de comércio realizadas desde então, e todos os acordos negociados na Rodada Uruguai, concluída em 1994 (THORSTENSEN, 1998, p. 30).

\footnotetext{
${ }^{22}$ Disponível em http://www.g20.org/index.php/en/g20. Acesso em: 29 out. 2012.

${ }^{23}$ Disponível em http://www.wto.org/english/thewto_e/whatis_e/whatis_e.htm. Acesso em: 29 out. 2012.
} 
Sequência do Acordo Geral de Tarifas e de Comércio (GATT - em inglês General Agreement on Tariffs and Trade), de 1947, a OMC originouse, em 1995, como mecanismo institucionalizador dos Acordos de Marraqueche de 1994 (conclusão da Rodada do Uruguai).

Conforme o artigo III, do Acordo de Marraqueche, que estabelece a Organização Mundial do Comércio, as funções deste organismo estão assim elencadas:

1. The WTO shall facilitate the implementation, administration and operation, and further the objectives, of this Agreement and of the Multilateral Trade Agreements, and shall also provide the framework for the implementation, administration and operation of the Plurilateral Trade Agreements.

2. The WTO shall provide the forum for negotiations among its Members concerning their multilateral trade relations in matters dealt with under the agreements in the Annexes to this Agreement. The WTO may also provide a forum for further negotiations among its Members concerning their multilateral trade relations, and a framework for the implementation of the results of such negotiations, as may be decided by the Ministerial Conference. 3. The WTO shall administer the Understanding on Rules and Procedures Governing the Settlement of Disputes (hereinafter referred to as the "Dispute Settlement Understanding” or "DSU") in Annex 2 to this Agreement.

4. The WTO shall administer the Trade Policy Review Mechanism (hereinafter referred to as the "TPRM") provided for in Annex 3 to this Agreement.

5. With a view to achieving greater coherence in global economic policymaking, the WTO shall cooperate, as appropriate, with the International Monetary Fund and with the International Bank for Reconstruction and Development and its affiliated agencies.

Ademais disso, a função básica da OMC, segundo seu site oficial, é "to ensure that trade flows as smoothly, predictably and freely as possible" 24 .

Todos os BRICS fazem parte desta organização, tendo a Rússia acedido à OMC somente no ano de 2011, após 18 anos de intensas negociações, tornando-se o $156^{\circ}$ membro ${ }^{25}$. África do Sul, Brasil e Índia são membros desde sua gênese em $1^{\circ}$ de janeiro de 1995, e China, por sua vez, desde 11 de dezembro de 2001.

${ }^{24}$ Disponível em http://www.wto.org/. Acesso em: 30 out. 2012.

${ }^{25}$ Disponível em http://europa.eu/rapid/press-release_IP-12-906_pt.htm?locale=en. Acesso em: 30 out. 2012. 
Para entrar na OMC, o país solicitante enfrenta um processo de acessão, perpassando uma agitada agenda de negociações bilaterais e multilaterais com os principais parceiros comerciais, a fim de adequar suas normas internas às propostas dos Acordos que balizam as negociações comerciais internacionais em diversos aspectos. Essas conversações podem perdurar por anos, como no caso da Rússia.

No que concerne à atuação dos BRICS nesta instância, a Organização Mundial do Comércio pode desempenhar papel de relevância para a resolução de controvérsias entre os membros. Dessa maneira, é de se observar, segundo Sandra Polónia Rios (2012), que “[...] na agenda do sistema multilateral do comércio os interesses de Brasil, China e Índia [os maiores protagonistas na OMC entre os BRICS] são predominantemente divergentes".

Nesse sentido, ademais, vê-se que:

Nas negociações comerciais no âmbito da OMC, a coalizão BRIC [sic] foi pouco relevante na definição da posição negociadora de seus integrantes. Nesta área, o principal protagonista foi o G-20 [Comercial], constituído em 2003, coalizão que integra Brasil, Índia, China e África do Sul entre outros países em desenvolvimento. Dessa maneira, dentro do G-20 [Comercial] a articulação dos BRIC [sic] foi pouco relevante para a tomada de decisão, especialmente devido a divergências em temas importantes da agenda, que ficaram explícitas na reunião miniministerial de julho de 2008 (LIMA, 2010, p. 170).

Embora haja pontos de divergências em questões comerciais, concordâncias ainda são possíveis. Nessa linha, já houve convergência de posições na OMC entre Brasil, Índia, China e África do Sul, no emblemático caso da formação de uma coalizão de países em desenvolvimento em prol das discussões sobre as negociações agrícolas levantadas na Rodada Doha. Essa coalizão é o G20 Comercial.

O nascimento da coalizão do G20 Comercial, segundo Pecequilo (2010), "encontra-se diretamente relacionado ao processo de negociações comerciais da OMC (Rodada Doha), Reunião de Cancún”. Essa reunião no México, realizada entre os dias 10 e 14 de setembro de $2003^{26}$, foi a quinta Conferência

${ }^{26}$ Disponível em http://www.wto.org/english/thewto_e/minist_e/min03_e/min03_e.htm. Acesso em: 30 out. 2012. 
Ministerial da OMC, cujo objetivo era o avanço na agenda de liberalização agrícola da Rodada Doha ${ }^{27}$. No entanto, este encontro não logrou êxito e foi tido como um dos maiores fracassos para as negociações comerciais, sendo amplamente divulgado na mídia ${ }^{28}$.

Como salienta Lima (2010):

A criação do G-20 [Comercial] ocorreu em reação à proposta conjunta dos EUA-UE sobre agricultura apresentada às vésperas da Reunião Ministerial de Cancun, de 2003, que ameaçou reduzir as ambições da Rodada Doha nas questões agrícolas, em contradição com a "Agenda de Desenvolvimento" adotada no início das negociações (LIMA, 2010, p. 170).

Assim, percebe-se que a formação desses tipos de alianças, visando ao contrabalanceamento do poder decisório de países desenvolvidos em detrimento da grande maioria de países em desenvolvimento, já refletia aceitação por este último grupo de países em agregar esforços para oporem-se às imposições do mundo desenvolvido.

Nessa esteira, o Embaixador Valdemar Carneiro Leão (2012), sherpa do Brasil no G20 Financeiro, sustenta que:

Na diplomacia econômica nenhum campo tem sido mais fértil para o aparecimento de grupos e alianças que o das negociações comerciais multilaterais, em que se observa a aglutinação de países, em múltiplas geometrias, ditadas por coincidência de interesses em temas ou mesmo em tópicos muitos específicos (LEÃO, 2012, p. 49).

A composição da aliança do G20 ${ }^{29}$ Comercial é variável e não expressa a numeração desta sigla, consoante Pecequilo (2010):

Desde sua criação, a quantidade de membros do G20 [Comercial] varia, tanto que em suas origens o grupo ficou conhecido como G20 plus. A composição do G20 [Comercial] é: Brasil, Argentina, Bolívia, Chile, Cuba,

\footnotetext{
${ }^{27}$ Informações disponíveis em http://www.wto.org/english/thewto e/minist e/min03 e/min03 e.htm. Acesso em: 30 out. 2012.

28 A BBC Brasil montou uma página especial com as notícias sobre a Reunião de Cancún de 2003. Disponível em http://www.bbc.co.uk/portuguese/noticias/cluster/2003/09/s omc.shtml. Acesso em: 30 out. 2012.

${ }^{29}$ É relevante observar a diferença deste G20, também denominado G20 Comercial, no domínio da OMC, para o G20, ou G20 Financeiro, no domínio do FMI, este último com maior predominância nos assuntos econômicos internacionais.
} 
Equador, Guatemala, México, Paraguai, Peru, Uruguai, Venezuela, nas Américas; China, Filipinas, Índia, Indonésia, Paquistão e Tailândia, na Ásia; África do Sul, Egito, Nigéria, Tanzânia e Zimbábue, na África (PECEQUILO, 2010, p. 272).

A despeito das divergências em termos de negociações comerciais encontradas no interior dos BRICS, ainda assim é possível vislumbrar um quadro de atuação conjunta, e portanto de influência, no âmbito da OMC, especialmente no tocante a questões de produtos agrícola, manufaturados e serviços.

O mecanismo do G20 Comercial, se reavivado pelos BRICS, poderá servir aos interesses dessas nações na agenda comercial, em especial nos temas de consenso, no entanto temas sensíveis deverão ser negociados de parte a parte para se tentar chegar a um ponto comum.

Concluindo, no contexto de aparecimento de atores relevantes no comércio internacional, a formação de coalizões desponta como mecanismo de articulação e pressão eficientes, cuja soma de poder mostra-se substancioso contrapeso às economias do mundo desenvolvido. Diante disso, o comércio internacional tem ganhado crescente participação dos países emergentes e, assim como na vertente econômico-financeira, deverá se remodelar na econômico-comercial, como mostram os números abaixo expostos do comércio intra-BRICS e de sua participação no comércio internacional.

\subsection{Os BRICS e o comércio internacional}

A prática econômica de comércio pressupõe a existência de algum produto de troca, o que evidencia a distribuição dos processos produtivos em todo o mundo, adentrando nas teorias do comércio internacional.

A importância desta prática afeiçoa-se às economias emergentes do mundo contemporâneo, em especial aos países do acrônimo BRICS ora em análise. Decerto, sobre esta dimensão, muito há que se analisar. Esta seção, sem pretensão de aprofundar o conhecimento sobre os constantes fluxos do comércio internacional, limita-se a expor, resumidamente, a participação de Brasil, Rússia, Índia, China e África do Sul nessa esfera econômica.

Nesse sentido, Lenina Pomeranz (2012) apresenta a Tabela 3 abaixo em que podemos verificar as correntes comerciais intra-BRICS: 


\section{TABELA 3 - CORRENTES DE COMÉRCIO ENTRE OS PAÍSES DO GRUPO BRICS}

(\% em relação às correntes totais de cada país indicado nas linhas)

\begin{tabular}{|l|c|c|c|c|c|}
\hline & Brasil & China & Índia & Rússia & Afr. Sul \\
\hline Brasil $^{(1)}$ & xxx & 16,6 & 1,98 & 1,62 & $0,55^{(2)}$ \\
\hline China $^{(3)}$ & 3,6 & xxx & 3,7 & 3,3 & 1,4 \\
\hline Índia $^{(4)}$ & 1,2 & 10,2 & xxx & 0,8 & 1,8 \\
\hline Rússia $^{(5)}$ & 1,1 & 9,8 & 1,9 & xxx & xxx \\
\hline Afr. Sul $^{(6)}$ & 0,55 & 1,4 & 1,8 & xxx & xxx \\
\hline
\end{tabular}

Fontes dos dados brutos

Brasil. Ministério do Desenvolvimento, Comércio e Indústria. DEPLA. Estatisticas do Comércio Exterior: China. China Statistical Yearbook 2010.

Índia. Reserve Bank of India. Directorate General of Commercial Intelligence and Statistics.

Rússia. Goskmstat. Statisticheskii Ejegodnik 2010.

Notas: (1) janeiro/setembro 2011; (2) janeiro/setembro 2010; (3) 2010; (4) abril 2010/março 2011; (5) 2009, último ano para o qual existem dados discriminados por país; (6) dados derivados das correntes comerciais mantidas com os demais países.

Fonte: POMERANZ, Lenina. MESA-REDONDA: O Brasil, os BRICS e a Agenda Internacional. In FONSECA Jr., Gelson et al. O Brasil, os BRICS e a agenda internacional. - Brasília: FUNAG, 2012, p. 125.

Constata-se da Tabela 3 que a relação comercial entre os BRICS pende seu peso para as trocas do grupo com a China, uma vez que ela possui os maiores índices percentuais de participação individual nas economias restantes do acrônimo. Essa assimetria revela, pois, maior dinâmica da economia chinesa em detrimento das outras.

Em termos de partilha do comércio internacional, segundo o Brics Report (2012), publicação realizada por acadêmicos e especialistas, a Tabela 4 a seguir apresenta as fatias detidas por cada um dos países do BRICS.

A China, segundo a publicação, mostra um crescimento vertiginoso na participação do comércio internacional. Isso se explica porque, segundo Chernavsky \& Leão (2010):

A partir das reformas econômicas promovidas pelo governo, após a ascensão ao poder de Deng Xiaoping no final da década de 1970, a economia chinesa passou por profundas transformações que modificaram de modo radical a estrutura produtiva interna, assim como o padrão de inserção externa do país. Desde então, o produto interno bruto (PIB) da China se multiplicou por 
quinze vezes em termos reais, crescendo a uma taxa média de quase $10 \%$ ao ano (a.a.), valor muito superior ao de qualquer outro país neste período (CHERNAVSKY \& LEÃO, 2010, p. 69).

\section{TABELA 4 - PARTICIPAÇÃO DOS BRICS NO COMÉRCIO INTERNACIONAL (EM \%)}

\begin{tabular}{lrrrrrrr}
\hline & 1990 & 1995 & 2000 & 2005 & 2008 & 2009 & 2010 \\
\hline BRICS & 3.6 & 6.0 & 7.0 & 11.2 & 13.6 & 13.7 & 15.0 \\
\hline Brazil & 0.8 & 0.8 & 0.8 & 1.0 & 1.1 & 1.1 & 1.2 \\
Russia & & 1.5 & 1.4 & 2.1 & 2.6 & 2.2 & 2.3 \\
\hline India & 0.5 & 0.6 & 0.7 & 1.2 & 1.5 & 1.6 & 1.8 \\
China & 1.6 & 2.6 & 3.5 & 6.4 & 7.9 & 8.3 & 9.2 \\
\hline South Africa & 0.6 & 0.5 & 0.5 & 0.5 & 0.5 & 0.5 & 0.5 \\
\hline
\end{tabular}

Fonte: The BRICS Report: A Study of Brazil, Russia, India, China, and South Africa with special focus on synergies and complementarities. India: Oxford University Press, 2012, p. 33.

Por seu turno, a Índia conseguiu sair de um patamar de 0,7\%, em 2000, para 1.8\%, em 2010. Esse progressivo aumento deveu-se às reformas de 1991, em que "[...] o governo realizou alterações importantes no eixo dessa política [comercial], buscando equacionar o déficit comercial resultante da ampliação mais que proporcional das importações em relação às exportações” (LEÃO \&OLIVEIRA, 2010).

A Rússia, tida por "economia em transição" ${ }^{30}$, obteve um crescimento de 1,4\%, em 2000, para 2,3\%, em 2010. Nesse mesmo período, o Brasil, por sua vez, não teve crescimento significativo, como se pode ver, saindo de $0,8 \%$ para $1,2 \%$, com crescimento de $0,4 \%$, devido a pouca abertura de sua economia. A África do Sul manteve-se estável na partilha do comércio internacional em $0,5 \%$.

\footnotetext{
${ }^{30}$ Termo utilizado por Ribeiro \& Moraes. De BRIC a BRICS: Como a África do Sul ingressou em um clube de gigantes. Boletim de economia e política internacional/Instituto de Pesquisa Econômica Aplicada. Diretoria de Estudos e Relações Econômicas e Políticas Internacionais. - n.1, (jan./mar. 2010 - ). - Brasília: IPEA/Dinte, 2010.
} 
Vê-se que ainda há espaço de crescimento das participações individuais de cada BRICS no comércio internacional, e que, no seu conjunto, os BRICS aumentaram a fatia do comércio internacional de forma substantiva de 7,0\%, em 2000, para 15\%, em 2010, aumento de 8,0 pontos percentuais.

Quanto às participações nas exportações e importações globais, esses países intermediários quedam-se conforme a Tabela 5 abaixo, também extraída do Brics Report.

\begin{tabular}{|c|c|c|c|c|c|c|c|}
\hline & 1990 & 1995 & 2000 & 2005 & 2008 & 2009 & 2010 \\
\hline BRICS & 3.9 & 6.5 & 7.5 & 12.2 & 14.8 & 15.1 & 16.3 \\
\hline Brazil & 0.9 & 0.9 & 0.9 & 1.1 & 1.2 & 1.2 & 1.3 \\
\hline Russia & - & 1.6 & 1.6 & 2.3 & 2.9 & 2.4 & 2.6 \\
\hline India & 0.5 & 0.6 & 0.7 & 0.9 & 1.2 & 1.3 & 1.4 \\
\hline China & 1.8 & 2.9 & 3.9 & 7.3 & 8.9 & 9.6 & 10.4 \\
\hline South Africa & 0.7 & 0.6 & 0.5 & 0.5 & 0.5 & 0.5 & 0.6 \\
\hline
\end{tabular}

Fonte: The BRICS Report: A Study of Brazil, Russia, India, China, and South Africa with special focus on synergies and complementarities. India: Oxford University Press, 2012, p. 37.

No que se refere à participação dos BRICS nas exportações mundiais, a Tabela 5 acima explicita os valores em porcentagem que cada componente detém. Permanece visível que a China é a maior detentora neste segmento com 10,4\% em 2010, em detrimento à participação de 1,3\% de Brasil, 2,6\% de Rússia, $1,4 \%$ de Índia e $0,6 \%$ de África do Sul. Os BRICS em conjunto possuem 16,3\% das exportações mundiais, número bastante expressivo, com tendências de crescimento futuro.

De outro lado, a absorção por esses países dos produtos internacionais, ainda evidencia o maior peso da China dentro da coalizão com um vigoroso crescimento de 3,4\%, em 2000, para 9,1\%, em 2010. Os demais países somam juntos, em 2010, 5,7\% das importações mundiais, abaixo 3,4\% do total que a China logrou no mesmo período. 
Esses números mostram a grandeza conjunta da coalizão BRICS em sua atuação no comércio internacional. Com ressalva de que, se não em conjunto, a participação de cada membro (Brasil, Rússia, Índia e África do Sul), separadamente, é irrelevante, excetuando-se a grande China, a qual figura entre as grandes economias com participação substantiva no comércio internacional.

\section{TABELA 6 - PARTICIPAÇÃO DOS BRICS NAS IMPORTAÇÕES MUNDIAIS (EM \%)}

\begin{tabular}{lrrrrrrr}
\hline & 1990 & 1995 & 2000 & 2005 & 2008 & 2009 & 2010 \\
\hline BRICS & 3.3 & 6.1 & 6.2 & 10.0 & 12.5 & 13.3 & 14.8 \\
\hline Brazil & 0.6 & 1.0 & 0.9 & 0.7 & 1.1 & 1.1 & 1.3 \\
Russia & - & 1.3 & 0.7 & 1.3 & 2.0 & 1.7 & 1.8 \\
\hline India & 0.7 & 0.7 & 0.8 & 1.3 & 2.0 & 2.0 & 2.1 \\
China & 1.5 & 2.5 & 3.4 & 6.1 & 6.9 & 8.0 & 9.1 \\
\hline South Africa & 0.5 & 0.6 & 0.5 & 0.6 & 0.6 & 0.6 & 0.5 \\
\hline
\end{tabular}

Fonte: The BRICS Report: A Study of Brazil, Russia, India, China, and South Africa with special focus on synergies and complementarities. India: Oxford University Press, 2012, p. 34.

\subsection{Premissas da Goldman Sachs e projeções do FMI sobre os BRICS}

As previsões realizadas em 2001 pela Goldman Sachs ${ }^{31}$ voltaram os olhares dos mercados internacionais aos países em desenvolvimento, especialmente a Brasil, Rússia, Índia e China. As afirmações do estudo Building Better Global Economic BRICs (O’NEILL, 2001) ${ }^{32}$, que embasaram a alavancagem da imagem destas nações emergentes, foram as seguintes:

\footnotetext{
${ }^{31}$ The Goldman Sachs Group, Inc. is a leading global investment banking, securities and investment management firm that provides a wide range of financial services to a substantial and diversified client base that includes corporations, financial institutions, governments and high-net-worth individuals. Disponível em http://www.goldmansachs.com/who-we-are/at-a-glance/index.html). Acesso em: 10 set. 2012.

${ }^{32}$ Paper $\mathrm{n}^{\circ}$ 66, de Jim O’Neill, disponível em http://www.goldmansachs.com/our-thinking/brics/bricsreports-pdfs/build-better-brics.pdf. Acesso em: 10 set. 2012.
} 
- In 2001 and 2002, real GDP growth in large emerging market economies will exceed that of the G7;

- At end-2000, GDP in US\$ on a PPP basis in Brazil, Russia, India and China (BRIC) was about 23.3\% of world GDP. On a current GDP basis, BRIC share of world GDP is $8 \%$;

- Using current GDP, China's GDP is bigger than that of Italy;

- Over the next 10 years, the weight of the BRICs and especially China in world GDP will grow, raising important issues about the global economic impact of fiscal and monetary policy in the BRICs;

- In line with these prospects, world policymaking forums should be reorganised and in particular, the G7 should be adjusted to incorporate BRIC representatives(O’NEILL, 2001, p. 1).

As informações trazidas por esse paper $n^{0} 66$ consubstanciaram expectativas dos investidores mundiais quanto às economias do acrônimo BRIC - ainda sem a inclusão da África do Sul. Adicionalmente, desenharam um futuro de crescente importância desses países nos foros internacionais.

Em paper posterior, de número 99, intituladoDreaming With BRICs: The Path to 2050, Dominic Wilson\&Roopa Purushothaman (2003), dois consultores da Goldman Sachs, reforçaram as previsões de O’Neill contidas no paper $N^{\circ} 66$, sustentando as seguintes premissas:

- Durante os próximos 50 anos, Brasil, Rússia, Índia e China - as economias do BRICs- podem se tornar uma força muito maior na economia mundial. [...] - Os resultados são surpreendentes. Se as coisas correrem bem, em menos de 40 anos, as economias dos BRICs juntas poderão ser maiores do que as do G6 [este é composto por Alemanha, Estados Unidos, França, Itália, Japão e Reino Unido] em termos de dólar americano. Até 2025 eles poderão representar mais de metade do tamanho do G6. Do atual G6, apenas os EUA e o Japão estarão entre as seis maiores economias em termos de dólar americano em 2050.

-A lista das dez maiores economias do mundo poderá parecer completamente diferente em 2050. As maiores economias do mundo (por PIB) podem não mais ser os mais ricos (por renda per capita) fazendo escolhas estratégicas para as empresas mais complexas. (WILSON \&PURUSHOTHAMAN, 2003, p. 1, Tradução e grifos nossos).

Na linha dessas premissas, Wilson \& Purushothaman (2003) elaboraram um gráfico no qual mostram suas projeções para a ultrapassagem das economias dos países do acrônimo BRICS em relação aos demais países do mundo desenvolvido, como se pode ver abaixo. 


\section{GRÁFICO 1 - ULTRAPASSANDO O G6: QUANDO AS ECONOMIAS DOS BRICS SUPERARÃO AS ECONOMIAS DO G6 (PIB EM US\$ DOLÁRES)}

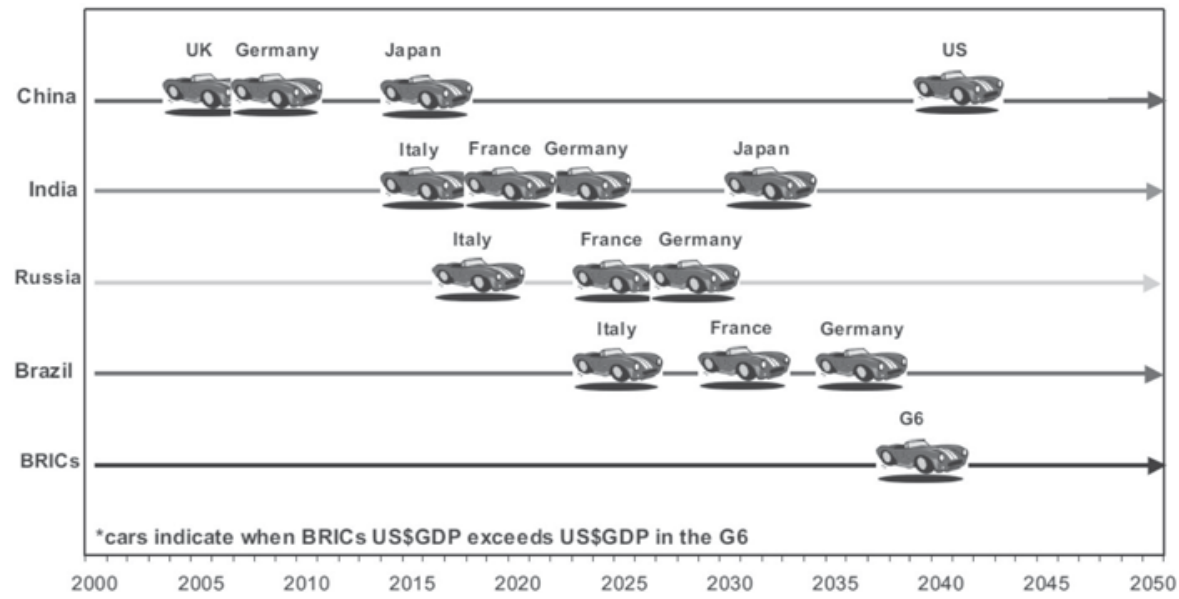

Fonte: Dreaming With BRICs: The Path to 2050. Paper 99. 2003, p. 3

A linha à frente do nome de cada membro do BRICS demonstra quando cada economia, segundo a projeção, superará àquelas do denominado G6. Como se pode ver, a previsão era de que a economia chinesa superasse à japonesa somente em 2020, o que aconteceu dez anos antes, em $2010^{33}$.

Por seu turno, o Reino Unido, embora não esteja representado na linha de projeção do Brasil, foi superado por este país em 2011. O Brasil alcançou o posto de $6^{\text {a }}$ maior economia do mundo ${ }^{34}$.

Em continuidade, o Fundo Monetário Internacional (FMI), em seu relatório World Economic Outlook (WEO), no mês de outubro de 2012, apresentou estimativas de crescimento de todos os países do globo, alguns dados apresentam-se na Tabela 7 abaixo.

\footnotetext{
${ }^{33}$ A mídia nacional e internacional divulgou, amplamente, a superação da economia do Japão pela China, como se pode ver da notícia da BBC Brasil, cujo título é "China passa Japão e é $2^{a}$ maior economia mundial”. Disponível em http://www.bbc.co.uk/portuguese/noticias/2011/02/ 110214_china_japao_economia_rw.shtml. Acesso em: 7 nov. 2012.

34 "Brasil supera Reino Unido e se torna $6^{a}$ maior economia, diz entidade”. Disponível em http:// www1.folha.uol.com.br/bbc/1026219-brasil-supera-reino-unido-e-se-torna-6-maior-economia-dizentidade.shtml. Acesso em: 7 nov. 2012.
} 
TABELA 7 - PROJEÇÕES DE CRESCIMENTO DO PIB DAS ECONOMIAS EMERGENTES E DO BRICS (ANOS 2010, 2011, 2012 E 2013)

\begin{tabular}{|c|c|c|c|c|}
\hline & $\mathbf{2 0 1 0}$ & $\mathbf{2 0 1 1}$ & $\mathbf{2 0 1 2}$ & $\mathbf{2 0 1 3}$ \\
\hline Crescimento Mundial & 5.1 & 3.8 & 3.3 & 3.6 \\
\hline Economias Desenvolvidas & 3.0 & 1.6 & 1.3 & 1.5 \\
\hline Economias Emergentes & 7.4 & 6.2 & 5.3 & 5.6 \\
\hline Brasil & 7.5 & 2.7 & 1.5 & 4.0 \\
\hline Rússia & 4.3 & 4.3 & 3.7 & 3.8 \\
\hline Índia & 10.1 & 6.8 & 4.9 & 6.0 \\
\hline China & 10.4 & 9.2 & 7.8 & 8.2 \\
\hline África do Sul & 2.9 & 3.1 & 2.6 & 3.0 \\
\hline
\end{tabular}

Fonte: Elaboração própria com base nos dados do World Economic Outlook (WEO), Outubro de 2012, p. 2.

Verificam-se da Tabela 7 acima as projeções de crescimento das economias do mundo desenvolvido, dos emergentes, dos BRICS separadamente, além do desempenho do crescimento do PIB mundial, realizadas pelo Fundo Monetário Internacional para os anos de 2012 e 2013, com crescimento consolidado em 2010 e 2011.

Pelos dados da Tabela 7, percebe-se, adicionalmente, intensa desaceleração dos BRICS em 2012, comparado com o crescimento em 2010. Isso em parte se explica pela crise econômica mundial de 2008, que se abateu fortemente sobre as economias desenvolvidas e que atrapalhou e continua atrapalhando - o crescimento dos demais países do globo, e pelas políticas protecionistas adotadas como consequências daquela crise.

No que se refere ao comércio internacional, os dados do FMI demonstram pouca oscilação nas projeções entre 2011 e 2013, mas brusca redução do intercâmbio mundial quando comparado com 2010, ápice de todos os indicadores de crescimento econômico e incremento do comércio, como se mostra abaixo.

Esses indicadores apontam para uma redução dos fluxos do comércio internacional e a necessidade de se coordenar políticas macroeconômicas mais consistentes, as quais limitem os impulsos protecionistas e permitam o retorno 
normal das trocas internacionais na pré-crise. Para isso, regimes de governança global como o G20 Financeiro, FMI e a OMC serão instrumentos fundamentais.

TABELA 8 - PROJEÇÕES PARA O COMÉRCIO INTERNACIONAL (ANOS 2010, 2011, 2012 E 2013)

\begin{tabular}{|c|c|c|c|c|}
\hline \multicolumn{5}{|c|}{ Ano após ano } \\
\hline \multicolumn{4}{|c|}{ Projeções } \\
\hline $\begin{array}{c}\text { Volume do comércio mundial } \\
\text { (bens e serviços) }\end{array}$ & 12.6 & 5.8 & 3.2 & 4.5 \\
\hline $\begin{array}{c}\text { Importações Economias } \\
\text { Emergentes }\end{array}$ & 14.9 & 8.8 & 7.0 & 6.6 \\
\hline $\begin{array}{c}\text { Exportações Economias } \\
\text { Emergentes }\end{array}$ & 13.7 & 6.5 & 4.0 & 5.7 \\
\hline
\end{tabular}

Fonte: Elaboração própria com base nos dados do World Economic Outlook (WEO), Outubro de 2012, p. 2.

\section{O BRASIL E OS BRICS NA GOVERNANÇA GLOBAL}

A formação de coalizões no mundo contemporâneo imprime a necessidade de rearranjos nas decisões globais, de modo que países menos favorecidos possam desfrutar de voz no processo construtivo da governança global.

Nesse sentido, é importante explicar que tudo dito até aqui em termos de redimensionamento de poder dentro das estruturas dos principais regimes políticos e econômicos internacionais refletem um contexto denominado governança global.

\subsection{A Governança Global e o agrupamento BRICS}

Segundo a Comissão sobre Governança Global da ONU, em estudo intitulado Our Global Neighbourhood. The Basic Vision (1995), a definição deste termo é:

[...]Governance is the sum of the many ways individuals and institutions, public and private, manage their common affairs. It is a continuing process 
through which conflicting or diverse interests may be accommodated and co-operative action may be taken. It includes formal institutions and regimes empowered to enforce compliance, as well as informal arrangements that people and institutions either have agreed to or perceive to be in their interest.

Por conseguinte, organizações internacionais e foros multilaterais de concertação como a ONU, OMC, FMI e G20 fazem parte da governança global, visto que acarretam mecanismos de coordenação para a harmonização de conflitos no cenário internacional, e que possuem atuação em áreas específicas, mas complementares.

Born \& Neuhaus (2007) trazem outra contribuição para o entendimento deste termo, segundo os autores:

O conceito de governança refere-se ao conjunto de iniciativas, regras, instâncias e processos que permitem às pessoas, por meio de suas comunidades e organizações civis, a exercer o controle social, público e transparente, das estruturas estatais e das políticas públicas, por um lado, e da dinâmica e das instituições do mercado, por outro, visando atingir objetivos comuns. Assim, governança abrange tanto mecanismos governamentais como informais e/ou não estatais. Significa a capacidade social (os sistemas, seus instrumentos e instituições) de dar rumo, ou seja, orientar condutas dos estados, das empresas, das pessoas em torno de certos valores e objetivos de longo prazo para a sociedade. (NEUHAUS \& BORN, 2007, p. 7) $)^{35}$.

Diante dessa afirmação, percebe-se que a governança global reflete a característica de pluralidade de visões e de tentativa de conciliá-las, com vistas a moldar entendimentos, bem como a necessidade de regras e instituições para que ela aconteça.

No que se refere às questões da política internacional, o entendimento deve estar presente nas diversas reuniões - formais e informais -, no âmbito das principais organizações internacionais de variadas temáticas (política, econômica, comercial, etc.), como a ONU, OMC, FMI e também no foro do G20 Financeiro.

${ }^{35}$ Disponível em http://www.frenteambientalista.org/downloads/governanca_ambientalFBOMSVC.pdf. Acesso em: 7 nov. 2012. 
Dessa forma, a Governança Global assume-se como inovação do incipiente processo “democrático” internacional no qual os estados da comunidade mundial posicionam-se sobre os temas que diretamente lhes afetam. Com isso, a inclusão dos BRICS no rol dos principais atores internacionais para a governança do mundo é importante porque propicia o surgimento de novos debates e a convergência (ou divergência) entre posições diferentes. Para tal finalidade, como se vê, o surgimento da coalizão BRICS mostra-se conveniente.

Sobre as coalizões, resta bastante claro que suas formações têm por objetivo enfrentar os desafios da globalização. De acordo com William A. Gamson (1961), em A theory of coalition formation, coalizões são:

[...]Coalitions are temporary, means oriented, alliances among individuals or groups which differ in goals. There is generally little value consensus in a coalition and the stability of a coalition requires tacit neutrality of the coalition on matters which go beyond the immediate prerogatives. [...] A coalition is the joint use of resources by two or more social units [...] (GAMSON, 1961, p. 364).

A definição de coalizões acima, no que concerne aos BRICS, coadunase com a inquietação do diplomata José Botafogo Gonçalves (2009), em artigo publicado na revista Política Externa, denominado "BRIC: sigla contingente ou permanente?”, sobre a inventividade da sigla BRIC e sua continuidade de atuação no palco internacional. O autor aponta o seguinte questionamento:

Diante deste quadro de diferenças, inconvergências e paradoxos [anteriormente apontados] cabe escolher entre alternativa de concluir que o BRIC é um fenômeno passageiro de mídia ou de marketing e não resistirá à ação do tempo; ou a de reconhecer fatores permanentes, embora não plenamente identificados, que garantirão a consolidação do grupo como foro privilegiado e de importância crescente no quadro das instituições existentes de governança global (GONÇALVES, 2009, p. 90, grifos nossos).

A preocupação quanto à efemeridade da associação entre os BRICS no contexto da governança global explica-se pelas expectativas de que, em conjunto, esses países poderão atuar firmemente nos processos decisórios 
internacionais, de modo a estabelecer equilíbrio de posições entre os países emergentes e os desenvolvidos, mormente nas causas a favor de nações pobres e de nações em situação de desenvolvimento similar.

Nesse contexto, o Brasil deverá vislumbrar a necessidade ou não de continuar a participar da coalizão BRICS, de acordo com suas prioridades de política externa, levando em consideração quais benefícios poderão ser auferidos dessa associação para sua projeção internacional. Abaixo, na última subseção, veremos o posicionamento brasileiro neste particular.

\subsection{O Brasil no BRICS}

A participação do Brasil nos BRICS tem estimulado inúmeros especialistas e estudiosos das relações internacionais a pesquisar sobre o fenômeno deste diálogo informal e sobre as perspectivas do país na participação dessa coalizão.

Segundo Rubens Barbosa (2012):

Do ponto de vista do Brasil, sua inclusão ao lado da China, Índia e Rússia talvez tenha sido o fator individual de maior relevância para projetá-lo externamente. Nenhuma campanha de divulgação do Brasil conseguiria essa façanha de marketing em tão curto espaço de tempo. Sem pedir, nem gastar recursos do Tesouro, passamos a integrar o grupo dos países emergentes mais importantes em um movimento que normalmente levaria décadas para ocorrer (BARBOSA, 2012, p. 245).

Ao que parece, conforme o autor, o Brasil possui uma visão de que o mecanismo BRICS é importante para sua atuação no cenário internacional. Nessa linha, de acordo com o Balanço de Política Externa 2003/2010, item 3.1.4 - Reforma da Governança Global - BRICS, publicado no site do Ministério das Relações Exteriores do Brasil, “O Brasil tem um papel atuante no mecanismo com grande destaque tanto para os temas econômicofinanceiros quanto para os de índole política”. Isso evidencia a amplitude de seu papel na coalizão.

Do que foi exposto nas páginas precedentes deste trabalho, a atuação conjunta dos BRICS tem muita a favorecer os componentes. Segue-se que, somente com o peso econômico associado dos integrantes, a alternativa de poder às potências ocidentais despontará. 
Ao acontecimento de criação de novas alianças, o ex-Ministro das Relações Exteriores e atual Ministro da Defesa, Celso Amorim, sustentou, em artigo, que:

O fato de criarmos novas associações não diminui a importância de outras alianças que o Brasil tem construído no governo Lula. É o caso do foro de cooperação com a África do Sul e a Índia, das cúpulas América do Sulpaíses árabes e África-América do Sul. É sobretudo o caso do processo de integração em nossa região, que ganhou impulso com a recente assinatura do tratado da Unasul ${ }^{36}$.

O Brasil participa de uma ampla rede de contatos diplomáticos, além dos BRICS, como afirmado por Celso Amorim, entre eles estão o MERCOSUL, legítimo mecanismo de integração econômico-comercial entre Brasil, Argentina, Uruguai e Paraguai, e, mais recente, Venezuela ${ }^{37}$; UNASUL - União de Nações Sul-Americanas - com vistas à integração política regional; IBAS, Fórum formal de articulação entre Índia, Brasil e África do Sul, três dos componentes da coalizão BRICS; entre diversos outros.

Esses foros e organizações dão dinamicidade à política externa do país e estão alinhados à sua prioridade de atuação. Os BRICS estão entre eles. No entanto, quais são os interesses do Brasil quanto a este último grupo de grandes emergentes?

A essa pergunta, Rubens Barbosa (2012) afirma que:

As grandes transformações que ocorrem no cenário internacional, no continente sul-americano e no Brasil dificultam a discussão interna com vistas a definir os reais e concretos interesses do Brasil. A crescente projeção externa do país, que exige novas formas de atuação na política externa e determinação de assumir responsabilidades, torna a definição dos interesses brasileiros no mundo um exercício complexo e de grandes sensibilidades interna e externa. [...] O que o Brasil quer da relação com esses países? Até aqui, não há resposta satisfatória (BARBOSA, 2012, p. 247).

\footnotetext{
${ }^{36}$ Disponível em http://www.itamaraty.gov.br/sala-de-imprensa/discursos-artigos-entrevistas-e-outrascomunicacoes/ministro-estado-relacoes-exteriores/86355815846-artigo-do-ministro-das-relacoesexteriores. Acesso em: 7 nov. 2012.

${ }^{37}$ Disponível em http://blog.planalto.gov.br/entrada-da-venezuela-no-mercosul-tem-significadohistorico-afirma-dilma/. Acesso em: 7 nov. 2012.
} 
Assim, aparenta que os interesses do Brasil dentro da coalizão BRICS não estão claros e que, portanto, delinear uma agenda em meio a modificações tão rápidas e constantes nas relações internacionais contemporâneas não tem sido fácil. Ainda de acordo com esse mesmo autor, “A mesma pergunta relacionada com os BRICS pode ser feita no tocante aos EUA e à China” (BARBOSA, 2012).

Nesse sentido, cabe salientar, ademais, que os BRICS estão buscando abrir espaço para a defesa de interesses que não estão totalmente claros se são para o bem coletivo ou individual.

A despeito disso, a atuação do Brasil nos BRICS irrompe como um relevante instrumento para a projeção diplomática do país no palco internacional. Seguindo o pensamento do Embaixador Marcos Azambuja: “É melhor ser BRICS do que não sê-lo” (FONSECA JR., 2012).

\section{CONSIDERAÇÕES FINAIS}

Este trabalho buscou apresentar elementos de consistência da participação de Brasil, Rússia, Índia, China e África do Sul no cenário internacional, na tentativa de responder à pergunta se eles são uma alternativa de poder às tradicionais potências ocidentais.

Versando, no aspecto qualitativo da análise, sobre os conceitos de poder e a multipolaridade do poder econômico, foi possível verificar qual o encaixe desses países emergentes no cenário internacional e como a representatividade geográfica da coalizão imprime o consequente aumento do poder político de Brasil, Rússia, Índia, China e África do Sul no âmbito das organizações internacionais.

Adicionalmente, elementos de análise macroeconômica, como o PIB e os números dos fluxos do comércio “intra” e "extra-BRICS”, foram trazidos à discussão de modo a sedimentar os argumentos e defender a hipótese da alternativa de poder na vertente quantitativa.

Visualizou-se que a importância dos BRICS de constituírem-se como alternativa de poder está fincada no contexto da governança global, visto que, dessa forma, poderão estabelecer um equilíbrio de posições nos processos decisórios internacionais.

Nesse sentido, a reivindicação da reforma dos principais regimes políticos e econômicos globais coaduna-se com a multiplicidade de vozes na concertação de soluções a problemas que afetam todo o globo. 
Inevitavelmente, à ampliação do poder econômico e político dos BRICS deverá seguir-se o fortalecimento da representação diplomática desses Estados nos foros multilaterais de concertação anteriormente abordados FMI, G20 Financeiro e OMC entre outros regimes internacionais de relevância.

Ao longo da pesquisa, foi possível perceber que os países desenvolvidos do G7 não poderão ditar as regras internacionais ao sabor de suas necessidades. A articulação com os BRICS será, de todo, necessária e indispensável.

Por fim, o Brasil precisará saber delinear quais os benefícios que deseja tirar da coalizão e como fazê-lo de modo a não prejudicar sua projeção internacional.

\section{REFERÊNCIAS}

\section{ALMEIDA, Paulo Roberto de. O BRIC e a substituição de} hegemonias: um exercício analítico (perspectiva histórico-diplomática sobre a emergência de um novo cenário global). In BAUMANN, Renato. (Org.). O Brasil e os demais BRICs - Comércio e Política. Brasília, DF: CEPAL. Escritório no Brasil/IPEA, 2010. pp. 131-154.

BALDUINO, Luis Antonio. A Crise Financeira Internacional como Oportunidade para a Reforma da Arquitetura Financeira Internacional. In Conferência Nacional de Política Externa e Política Internacional (4.: 2009 : Rio de Janeiro). IV Conferência Nacional de Política Externa e Política Internacional: $\boldsymbol{O}$ Brasil no mundo que vem aí. Brasília: FUNAG, 2010. pp. 101-115.

BARBOSA, Rubens. O Brasil e os BRICS: Policy Paper. In O Brasil, os BRICS e a Agenda Internacional. Brasília: FUNAG, 2012. pp. 245-251.

BAUMANN, Renato (Org.). O Brasil e os demais BRICS - Comércio e Política. Brasília, DF: CEPAL, Escritório no Brasil/IPEA, 2010.

BAUMANN, Renato. Os BRICS e o G20 financeiro. In O Brasil, os BRICS e a Agenda Internacional. Brasília: FUNAG, 2012. pp. 205-215. 
BOBBIO, Norberto; MATTEUCCI, Nicola; e PASQUINO, Gianfranco, Dicionário de Política, Brasília: Editora da UnB, 9a Ed. 1997. pp. 933943. Mario Stoppino.

BULL, Hedley. A sociedade anárquica: um estudo da ordem na política mundial. Tradução Sérgio Bath. $1^{\text {a }}$ ed. Brasília: Editora Universidade de Brasília, Instituto de Pesquisa de Relações Internacionais; São Paulo: Imprensa Oficial do Estado de São Paulo, 2002.

CARVALHO, Fernando J. Cardim de. A Crise Econômico-Financeira de 2007/2008, o G20 e as Opções para o Brasil. In Conferência Nacional de Política Externa e Política Internacional (5.: 2010 : Rio de Janeiro). V Conferência Nacional de Política Externa e Política Internacional: $\boldsymbol{O}$ Brasil no mundo que vem aí. - Brasília: FUNAG, 2010. pp. 69-82.

CHERNAVSKY, Emilio; LEÃO, Rodrigo Pimentel Ferreira. Capítulo 3 A evolução e as transformações estruturais do comércio exterior chinês. pp. 69-107. In ACIOLY, Luciana; LEÃO, Rodrigo Pimentel Ferreira. Comércio Internacional: aspectos teóricos e as experiências indiana e chinesa. Livro 1. Brasília: IPEA, 2010.

CLINTON, Hillary. A Smart Power Approach to Counterterrorism. John Jay College of Criminal Justice. 9 set. 2011. Vídeo disponível em http:// video.state.gov/en/video/1151631965001/a-smart-power-approach-tocounterterrorism. Acesso em: 30 set. 2012.

DEUTSCH, Karl Wolfgang. Análise das relações internacionais. Tradução Maria Rosinda Ramos da Silva. Brasília: Universidade de Brasília, 1982.

DUPAS, Gilberto. A Configuração Mundial do Poder, a Nova Hegemonia Norte-Americana e Novo Governo Obama. In MOSCARDO, Jeronimo; CARDIM, Carlos Henrique (Org.). III Conferência Nacional de Política Externa e Política Internacional (3 : Rio de Janeiro : 8 e 9 de dezembro de 2008). O Brasil no mundo que vem aí. - Brasília: FUNAG, 2009. pp. 33-51. 
FMI, World Economic Outlook (October, 2009): Sustaining the Recovery. International Monetary Fund. Disponível em http://www.imf.org/ external/pubs/ft/weo/2009/02/pdf/text.pdf. Acesso em 25 out. 2012.

FMI, World Economic Outlook (October, 2010): Recovery, Risk, and Rebalancing. International Monetary Fund. Disponível em http:// www.imf.org/external/pubs/ft/weo/2010/02/pdf/text.pdf. Acesso em 25 out. 2012.

FMI, World Economic Outlook (October, 2012): Coping with High Debt and Sluggish Growth. International Monetary Fund. Disponível em http:// www.imf.org/external/pubs/ft/weo/2012/02/pdf/text.pdf. Acesso em 25 out. 2012.

FONSECA Jr., Gelson. BRICS: notas e questões. In O Brasil, os BRICS e a Agenda Internacional. Brasília: FUNAG, 2012. pp. 13-30.

GONÇALVES, José Botafogo. BRIC: Sigla contingente ou permanente? Política Externa, São Paulo, vol. 18, nº 2, set/out/nov. 2009, pp. 89-97.

KENNEDY, Paul. Ascensão e queda das grandes potências: transformação econômica e conflito militar de 1500 a 2000. Tradução de Waltensir Dutra - 5a ed. - Rio de Janeiro: Campus, 1991.

KEOHANE, Robert O.; NYE, Joseph S. Power and Interdependence. $3^{\text {a }}$ ed. Pearson Education, 2001.

KRUGMAN, Paul; OBSTFELD, Maurice. Economia internacional: teoria e política. Tradução Eliezer Martins Diniz. Revisão técnica Rogério Mori, Paulo Gala. 8a ed. São Paulo: Pearson Prentice Hall, 2010.

LEÃO, Valdemar Carneiro. BRICS: identidade e agenda econômica. In O Brasil, os BRICS e a Agenda Internacional. Brasília: FUNAG, 2012. pp. 67-78. 
LEÃO, Rodrigo Pimentel Ferreira; OLIVEIRA, Ivan Tiago Machado. Capítulo 2 -Comércio exterior e política comercial indiana em análise. In ACIOLY, Luciana; LEÃO, Rodrigo Pimentel Ferreira.

Comércio Internacional: aspectos teóricos e as experiências indiana e chinesa. Livro 1. Brasília: IPEA, 2010. pp. 37-68.

LEBRUN, Gérard. O que é poder? Tradução Renato Janine Ribeiro, Sílvia Lara Ribeiro. São Paulo: Abril Cultural; Brasiliense, 1984.

LIMA, Maria Regina Soares de Lima. Brasil e polos emergentes do poder mundial: Rússia, Índia, China e África do Sul. In BAUMANN, Renato (Org.). O Brasil e os demais BRICS - Comércio e Política. Brasília, DF: CEPAL, Escritório no Brasil/IPEA, 2010. pp. 155-176.

MANKIW, N. Gregory. Introdução à Economia: princípios de micro e macroeconomia. $2^{a}$ ed. Tradução Maria José Cyhlar Monteiro. Rio de Janeiro: Elsevier, 2001.

MORGENTHAU, Hans. A política entre as nações: a luta pelo poder e pela paz. Tradução Oswaldo Biato. - Brasília: Editora Universidade de Brasília, Imprensa Oficial do Estado de São Paulo e Instituto de Pesquisa de Relações Internacionais, 2003.

OURO-PRETO, Affonso Celso de. Nova confirmação de poder. In O Brasil, os BRICS e a Agenda Internacional. Brasília: FUNAG, 2012. pp. 67-78.

O’NEILL, Jim. Building Better Global Economic BRICs. Paper n ${ }^{\circ} 66$. Nova Iorque: Goldman Sachs, 2001. Disponível em http:// www.goldmansachs.com/our-thinking/brics/brics-reports-pdfs/build-betterbrics.pdf. Acesso em: 25 ago. 2012.

PECEQUILO, Cristina Soreanu. Introdução às relações internacionais: temas, atores e visões. 6 ${ }^{\text {a }}$ ed.Petrópolis, Rio de Janeiro: Vozes, 2008. 
. Manual do candidato: política internacional. - Brasília:

Fundação Alexandre de Gusmão, 2009.

POMERANZ, Lenina. O Brasil, os BRICS e a agenda internacional. In O Brasil, os BRICS e a Agenda Internacional. Brasília: FUNAG, 2012. pp. 117-125.

REIS, Maria Edileuza Fontenele. BRICS: surgimento e evolução. In O Brasil, os BRICS e a Agenda Internacional. Brasília: FUNAG, 2012. pp. 31-47.

RIOS, Sandra Polónia. O que há em comum na agenda econômica dos BRICS?In O Brasil, os BRICS e a Agenda Internacional. Brasília: FUNAG, 2012. pp. 235-244.

SATO, Eiiti. A agenda internacional depois da Guerra Fria: novos temas e novas percepções. Rev. bras. polít. int. [online], vol. 43, n 1, pp. 138-169, jan./jun. 2000.Disponível em http://www.scielo.br/pdf/rbpi/v43n1/ v43n1a07.pdf. Acesso em 30 set. 2012.

THORSTEnSEN, Vera. A OMC - Organização Mundial do Comércio e as negociações sobre comércio, meio ambiente e padrões sociais. Disponível em http://www.scielo.br/pdf/rbpi/v41n2/v41n2a03.pdf. Acesso em: 30 out. 2012.

ZHEBIT, Alexander. BRIC: Uma Emergência Global das Novas Potências. In Conferência Nacional de Política Externa e Política Internacional (5.: 2010 : Rio de Janeiro). V Conferência Nacional de Política Externa e Política Internacional: $\boldsymbol{O}$ Brasil no mundo que vem aí. - Brasília: FUNAG, 2010. pp. 7-35.

WIGHT, Martin. A Política do Poder. Tradução Carlos Sérgio Duarte. $2^{\mathrm{a}}$ ed. Brasília: Editora Universidade de Brasília, Instituto de Pesquisa de Relações Internacionais; São Paulo: Imprensa Oficial do Estado de São Paulo, 2002. 
WILSON, Dominic; PURUSHOTHAMAN, Roopa. Dreaming With BRICs: The Path to 2050. Paper $n^{\circ}$ 99. Nova Iorque: Goldman Sachs, 2003. Disponível em http://www.goldmansachs.com/our-thinking/topics/ brics/brics-reports-pdfs/brics-dream.pdf. Acesso em: 18 jul. 2012.

Artigo recebido em: 15/11/2013 Aprovado para publicação em: 05/04/2014

Como citar: BIJOS, Leila. GUILHON, Erick Pessôa. Brics, uma alternativa de poder? Revista do Direito Público. Londrina, v.9, n.1, p.9-54, jan./abr.2014. DOI: 10.5433/1980-511X.2014v9n1p9. 